\title{
Experimental Techniques for Finite Shear Strain Measurement within Two Advanced High Strength Steels
}

\author{
N. Pathak*, C. Butcher, M. J. Worswick \\ Department of Mechanical and Mechatronics Engineering, University of Waterloo, Waterloo, ON, CANADA \\ *Corresponding author. Email: n3pathak@uwaterloo.ca
}

\begin{abstract}
There is a growing need to experimentally characterize local shear deformation in advanced high strength steels (AHSS) for the calibration of stress-state dependent fracture criteria and to better understand sheared edge cracking during secondary forming operations. Planar shear test specimens with digital image correlation (DIC) strain measurement are now commonly performed tests but may not be able to resolve the local strains during the final stage of fracture when the macroscopic shear band collapses to a micro-shear band with intense local strains. Studies of sheared edge stretching of AHSS have shown that the microstructure at the sheared edge experiences extreme local shear deformation with the shear-affected zone (SAZ) that can be much larger than the macroscopic strains reported using DIC on planar shear tests. In this work, two independent experimental techniques are proposed to characterize the residual strain distribution within the shear-affected zone for two AHSS grades with a similar strength level: a complex-phase (CP) steel, CP800, and a dual-phase (DP) steel, DP780. The first method uses finite strain theory to calculate the work-conjugate equivalent strain from grain rotations within the shear bands of interrupted in-plane shear tests. A comparison between the local DIC strain measurements and the grain rotation measurements were found to be in excellent agreement until just prior to failure. The second technique used microhardness measurements taken from the interrupted shear tests to develop correlations with the measured equivalent strain from the DIC system. The hardness and grain rotation techniques were then used to characterize the local strain distribution within the SAZ of hole expansion test specimens for punch clearances of $12 \%$ and $28 \%$. Both methods provided similar strain distributions with the grain rotation method having the highest strain resolution. The residual strain field within the SAZ of both AHSS was found to be strongly dependent upon the punch clearance. Finally, a homogenization procedure was applied to the SAZ strain distributions to facilitate the length scale transition from the grain-level to length scales appropriate for finite-element modelling of sheet metal forming operations with sheared edges.
\end{abstract}

Keywords: Shear strain, Sheared edge stretching, AHSS

\section{Introduction}

The past decade has seen rapid advancements in the fracture characterization of sheet materials with the development of a stress-state dependent methodology in which a proportional failure locus is constructed in terms of the stress invariants and the equivalent strain (Bao and Wierzbicki, 2004). For sheet metals, deformation can be idealized as plane stress, the variation of the failure strain is expressed in terms of the stress triaxiality from simple shear to biaxial 
stretching. The experimental and numerical methodology used in the Modified Mohr Coulomb (MMC) model of Bai and Wierzbicki $(2008,2010)$ along with the advent of digital image correlation (DIC) has led to tremendous improvements in the design and analysis of new test geometries for proportional stress states. Central hole tension tests have been developed for uniaxial tension that minimize necking (Bao and Wierzbicki, 2004; Dunand and Mohr, 2010; Roth and Mohr, 2016) or a machined conical hole expansion test can be used as proposed by Pathak et al. $(2016,2017)$. Plane strain tension tests using notched tensile tests are commonly used (Dunand and Mohr, 2010) or a severe-tight radius bend test can be employed to mitigate necking as done by Roth and Mohr (2016) and Cheong et al. (2017). Biaxial bulge or Nakazima dome tests are used to characterize fracture in equal-biaxial stretching. The trend for the variation of the failure strain from uniaxial tension to biaxial stretching is relatively wellunderstood in plane stress, with the lowest failure strain normally corresponding to the in-plane plane strain state (Luo and Wierzbicki, 2010).

Less well understood is the variation of the failure strain from simple shear to uniaxial tension, particularly if the failure strain in shear is higher or lower than in uniaxial tension. Furthermore, in the MMC model, a trough is generally predicted where the failure strain decreases in combined tension and shear such that a "cusp" exists at uniaxial tension as shown in Figure 1 for a DP780 from Anderson et al. (2017). This trend is in agreement with the experimental observations of Bao and Wierzbicki (2004) for AA2024-T351. Conversely, it can be argued that an exponential variation of failure strain with stress triaxiality should be expected such that the failure strain in shear should be higher than uniaxial tension. This functional dependence is expected from the solution of Rice and Tracey (1969) based upon void growth rates and an exponential dependence of failure strain on the stress triaxiality has been widely used, as in the model of Johnson and Cook (1985). Depending upon the failure mechanism of the material, it could be that a cusp is observed for shear-sensitive materials and not for other alloys where failure is dominated by void nucleation and coalescence. 


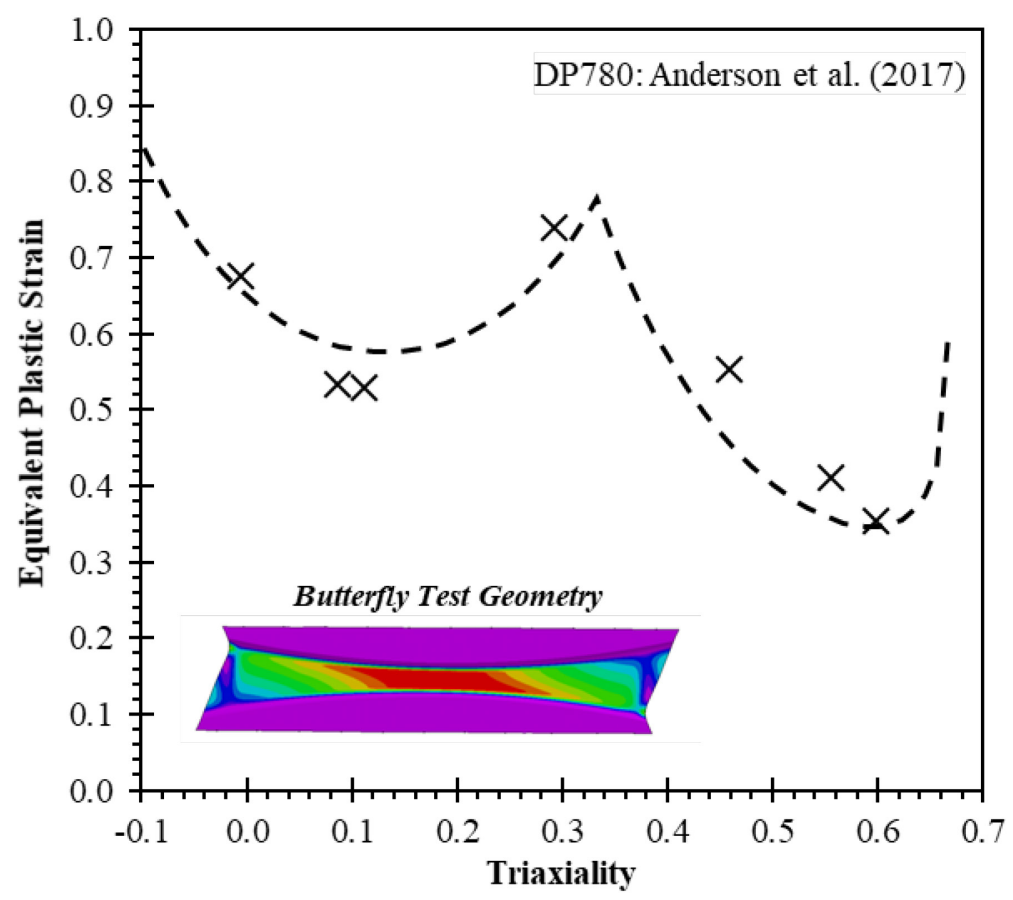

Figure 1: DP780 fracture locus obtained by Anderson et al. (2017) using inverse finite-element analysis of butterfly tests.

A significant source of uncertainty in shear characterization is due to the testing methods. Inplane shear tests are sensitive to fracture initiation at the edges and this has led to the development of multiple shear test geometries in the literature with recent tests such as in-plane torsion (Pohlandt and Tekkaya, 1985; Brosius et al., 2011), butterfly shear tests (Mohr and Henn, 2007; Dunand and Mohr, 2011), the "smiley" specimen of Roth and Mohr (2016) and the minishear of Piers et al. (2012). Three-types of in-plane shear geometries were compared in Yin et al. (2014) and by Abedini et al. (2016) for the mini-shear and butterfly test specimens. Recently, Papasidero et al. (2015) re-visited the fracture characterization of AA2024-T351 using tensiontorsion tests and reported higher failure strains in shear than the in-plane results of Bao and Wierzbicki (2004). Similarly, Scales et al. (2016) performed tension-torsion tests of AA6061-T6 and reported much higher failure strains in shear than the in-plane tests of Beese et al. (2010). The results of Scales et al. (2016) were in agreement with the very large failure strains in excess of 250\% in shear reported of Ghahremaninezhad and Ravi-Chandar (2013) for AA6061-T6 sheet based upon grain measurements using an in-plane shear test.

Aside from issues with potential edge cracking, a recent study by Rahmaan et al. (2017) using in-plane shear tests of a DP600 steel at elevated strain rates provides further insight into 
the issue of gage length on shear fracture characterization. A comparison of the DIC strains along with strains obtained from grain rotations revealed that the length-scale of the DIC did not capture the collapse of the macroscopic shear band into a microscopic shear band prior to fracture. At higher strain rates, the shear band localized at lower strain levels due to adiabatic softening such that the macroscopic failure strain and displacement to failure were observed to decrease with the strain rate. However, at the grain level, the local failure strains were actually increasing with strain rate. Understanding the variation of the shear failure strain with strain rate and length-scale also has direct applications to sheared edge cracking of advanced high strength steels (AHSS). Industrial shearing operations such as hole punching or trimming are generally performed at high speed and induce a severely work-hardened shear-affected zone (SAZ) behind the edge (Levy and van Tyne, 2012). Accurate characterization of this residual strain field is critical to enable the effect of the shearing operation on the subsequent sheared edge formability and to predict edge cracking in secondary forming operations along with the length-scale transition of the strain distribution in the SAZ to plane stress elements. A study by Pathak et al. (2016) on sheared edge cracking of AHSS using hole expansion tests has suggested that the dominant factor controlling cracking is the residual strain and damage distribution which in turn depends upon the shearing process parameters such as the clearance.

The need to develop and validate the experimental techniques for residual shear strain measurement across length-scales provides the motivation for the present study. Two advanced high strength steels, a $1.56 \mathrm{~mm}$ thick DP780 and a $2.9 \mathrm{~mm}$ thick CP800 are considered to provide a contrast between alloys of similar strength but vastly different local formability and sheared edge sensitivity. A series of in-plane shear tests were conducted to various strain levels with the strains measured using stereoscopic DIC. Microhardness measurements and grain rotation measurements were then taken at the same locations to develop correlations with the measured DIC strains. The grain rotation method is developed based upon the work-conjugate equivalent plastic strain for a von Mises material obtained from finite-strain theory where only the relative angle change is required. It will be demonstrated that both the hardness correlations and the grain rotation methods can provide similar results for the residual shear strains but with each having its own inherent gage length. Averaging of the high-resolution grain-rotation based measurements shows a convergence to the reported DIC strains and highlights the importance of 
the selected gage length in shear fracture characterization. Both strain measurement techniques are then applied to characterize the SAZ in sheared edges of CP800 and DP780 where extremely large shear failure strains are observed along with a strong influence of the punching clearance on the magnitude and distribution of the residual strain field which is known to significantly impacts edge cracking in subsequent forming operations.

\section{Methodology}

\subsection{Mechanical Properties}

The present investigation focuses on a prototype hot-rolled CP steel with an ultimate tensile strength of $800 \mathrm{MPa}$ and a commercial DP780 steel. The CP800 consists of a mostly bainitic microstructure with some ferrite and martensite whereas the DP780 is composed of ferrite and martensite. The mechanical properties of both steels were previously characterized in Pathak et al. (2016) and are summarized in Table 1 where YS is the yield strength, UTS is the ultimate tensile strength, TE is the total elongation, $n$, is the hardening exponent, $R$ is the Lankford coefficient ant RA is the reduction in area. The limiting direction for both alloys was the transverse direction (TD) that had the highest stress and lowest elongation. A comparison of the engineering stress-strain curves in Figure 2 shows how the CP800 has a much lower hardening rate than the DP780.

Table 1: Mechanical properties of the CP and DP steels obtained using subsize ASTM (ASTM E8/E8M-11, 2011) tensile specimens and a gauge length of $25 \mathrm{~mm}$. The value in the brackets is the standard deviation after three tests. (Pathak, et al., 2016)

\begin{tabular}{|c|c|c|c|c|c|c|c|c|}
\hline Material & $\begin{array}{c}\text { Thickness } \\
\text { (mm) }\end{array}$ & Direction & $\begin{array}{c}\mathrm{YS} \\
(\mathrm{MPa})\end{array}$ & $\begin{array}{c}\text { UTS } \\
(\mathrm{MPa})\end{array}$ & $\begin{array}{l}\mathrm{TE} \\
(\%)\end{array}$ & $\begin{array}{c}n \\
(5-U E \%)\end{array}$ & $R$ & $\begin{array}{l}\mathrm{RA} \\
(\%)\end{array}$ \\
\hline \multirow{3}{*}{ СР800 } & \multirow{3}{*}{2.90} & $\mathrm{RD}$ & $\begin{array}{l}710 \\
(6)\end{array}$ & $\begin{array}{l}810 \\
(3)\end{array}$ & $\begin{array}{l}19.6 \\
(1.7)\end{array}$ & $\begin{array}{c}0.08 \\
(0.00)\end{array}$ & $\begin{array}{c}0.70 \\
(0.04)\end{array}$ & \multirow{3}{*}{$\begin{array}{l}69 \\
(6)\end{array}$} \\
\hline & & TD & $\begin{array}{l}788 \\
(5)\end{array}$ & $\begin{array}{c}850 \\
(5)\end{array}$ & $\begin{array}{l}18.8 \\
(1.0)\end{array}$ & $\begin{array}{c}0.06 \\
(0.00)\end{array}$ & $\begin{array}{c}0.95 \\
(0.04)\end{array}$ & \\
\hline & & DD & $\begin{array}{l}726 \\
(8)\end{array}$ & $\begin{array}{l}800 \\
(5)\end{array}$ & $\begin{array}{l}20.5 \\
(2.0)\end{array}$ & $\begin{array}{c}0.07 \\
(0.00)\end{array}$ & $\begin{array}{c}1.33 \\
(0.03)\end{array}$ & \\
\hline \multirow{3}{*}{ DP780 } & \multirow{3}{*}{1.55} & $\mathrm{RD}$ & $\begin{array}{l}509 \\
(8)\end{array}$ & $\begin{array}{l}800 \\
(6)\end{array}$ & $\begin{array}{l}22.8 \\
(2.2)\end{array}$ & $\begin{array}{c}0.16 \\
(0.00)\end{array}$ & $\begin{array}{c}0.72 \\
(0.02)\end{array}$ & \multirow{3}{*}{$\begin{array}{l}41 \\
(4)\end{array}$} \\
\hline & & TD & $\begin{array}{l}522 \\
(4)\end{array}$ & $\begin{array}{l}806 \\
(5)\end{array}$ & $\begin{array}{l}21.6 \\
(1.8)\end{array}$ & $\begin{array}{c}0.15 \\
(0.00)\end{array}$ & $\begin{array}{c}0.92 \\
(0.03)\end{array}$ & \\
\hline & & DD & $\begin{array}{c}533 \\
(6)\end{array}$ & $\begin{array}{l}815 \\
(8)\end{array}$ & $\begin{array}{l}25.5 \\
(1.8)\end{array}$ & $\begin{array}{c}0.15 \\
(0.00)\end{array}$ & $\begin{array}{c}0.98 \\
(0.01)\end{array}$ & \\
\hline
\end{tabular}




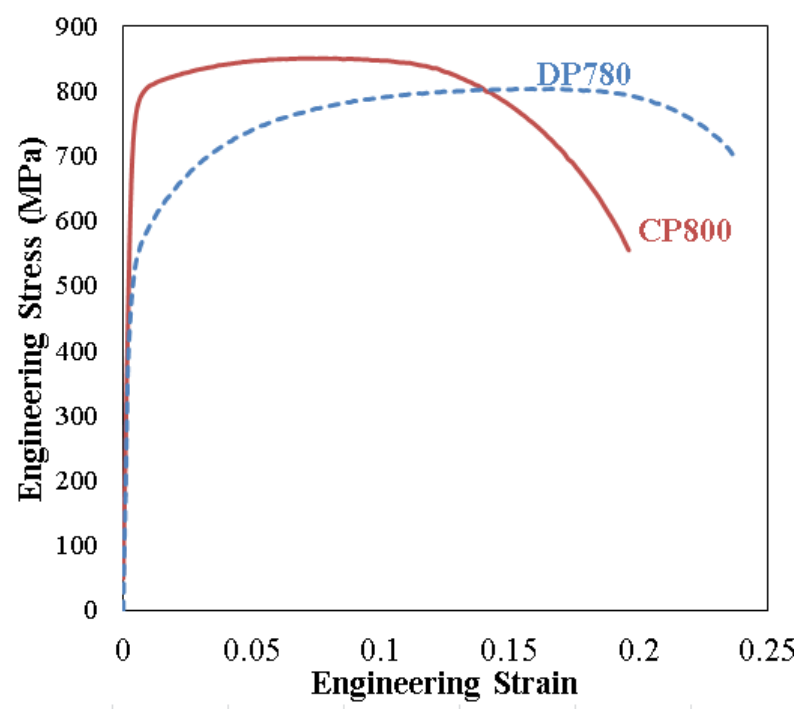

Figure 2: Engineering stress-strain curves (TD) for the CP800 and DP780 steels at $0.003 \mathrm{~s}^{-1}$ strain

\subsection{In-Plane Simple Shear Test}

In the present work, a series of interrupted shear tests was performed using the shear specimen geometry developed by Peirs et al. (2012) shown in Figure 3. The shear testing was conducted using a MTS Criterion Model 45 tensile frame at a cross-head displacement rate of $0.03 \mathrm{~mm} / \mathrm{s}$ that corresponds to a von Mises equivalent strain-rate of $0.01 \mathrm{~s}^{-1}$ at the center of the shear zone. As suggested by Abedini et al. (2017) for this shear geometry, the samples were fabricated in the diagonal direction of the sheet so that during the test, the principal stress direction will be aligned with the transverse direction of the sheet.

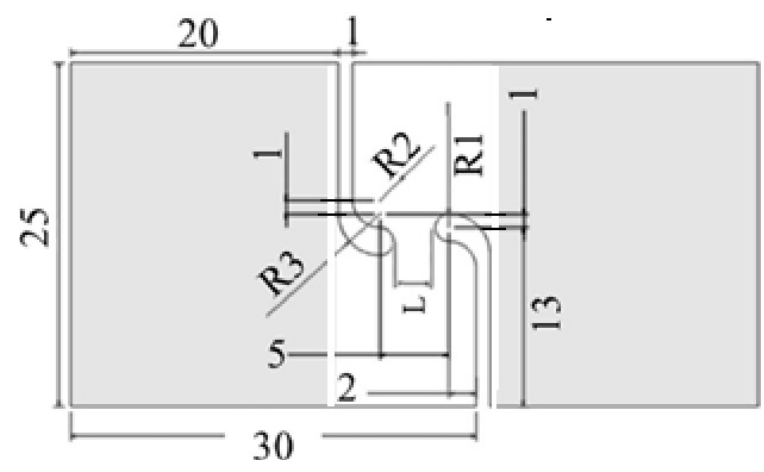

Figure 3: Simple shear specimen geometry adapted from Piers et al. (Peirs, et al., 2012). The shaded area corresponds to the clamped location during the test. 
Two cameras were used to record the experiment with a frame rate of 6 frames per second. Full-field logarithmic (true) strain measurements were obtained using the Vic-3D software from Correlated Solutions Inc. using the incremental correlation option to account for severe local strains. A subset size of 31 pixels was used for DIC analysis, with a step size of 3, strain filter size of 7 pixels to obtain and a resolution of $0.012 \mathrm{~mm} /$ pixel. In order to quantify the effects of step size and the strain filter size in the DIC analysis, the Virtual Strain Gauge Length (VSGL) of the mini-shear specimens was calculated using following equation.

$$
\text { VSGL }=\text { Resolution of the area of interest } \times \text { Step size } \times \text { Filter size }
$$

The VSGL is not directly used within the DIC software algorithm to calculate the strains, but is considered a metric to report the DIC analysis settings used in the experiments. A VSGL of $0.3 \mathrm{~mm}$ was obtained using the current DIC setting as recommended by Rahmaan et al. (2017) who reported that the local strain measurements converged at this resolution for the shear geometry in Figure 3. A contour plot of the major true strain for the CP800 is shown in Figure 4 where the maximum strain occurs at the center of the gage region. To extract the local strains, the procedure outlined by Rahmaan et al. (2017) was adopted by using circle inspector tools within the Vic-7 software with a circle diameter of $0.2 \mathrm{~mm}$. For each pixel contained within the circle the strain measurements are averaged with three circles in the shear zone shown in Figure 4.

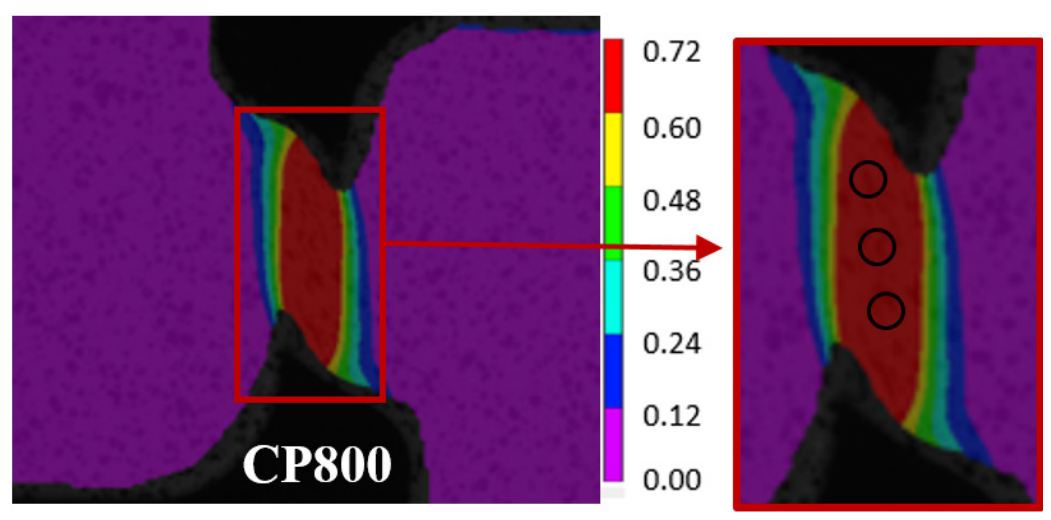

Figure 4: Major strain contour plot (left) of plastically deformed CP800 shear specimen. Magnified view (right) indicates three $0.2 \mathrm{~mm}$ diameter circles used as areas of interest considered in the DIC analysis

The mechanics of shear deformation enforce that the ratio of the minor to major strain $\left(\varepsilon_{2} / \varepsilon_{1}\right)$, is -1 as discussed in Abedini et al. (2017). The extracted principal strain ratios for the 
CP800 and DP780 are shown in Figure 5 where it can be seen that an approximately ideal simple shear condition prevails within the gage region until fracture. Similarly, as shown in Piers et al. (2012) and Abedini et al. (2017), the average shear stress for this shear geometry can be accurately estimated as:

$$
\tau_{\text {avg }}=\frac{F}{A_{\text {shear }}}=\frac{F}{L t}
$$

where $F$ is the force, $t$ is the thickness of the material, and $L$ is the length of the shear region with a nominal value of $3.0 \mathrm{~mm}$.

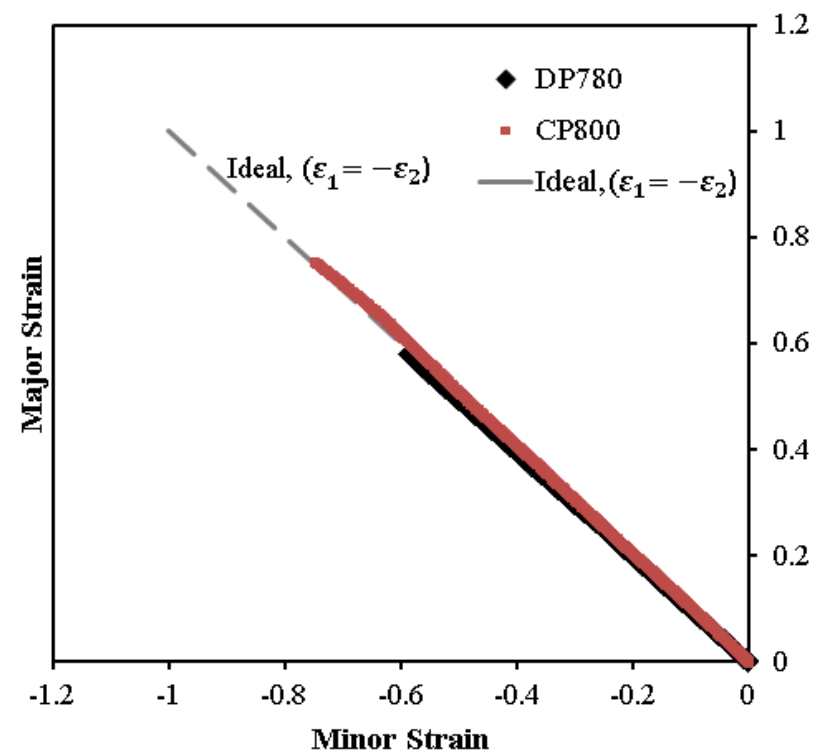

Figure 5: Comparison of the principal strains obtained from the DIC in the center of the shear band with the theoretical strain ratio for simple shear.

The onset of fracture in shear tests is difficult to detect visually so the Zener and Holloman (1944) criterion is employed where the onset of localization coincides with the hardening rate becoming negative. This criterion was recently employed by Rahmaan et al. (2017) where the onset of visible cracking and an increase in the local strain rate at the center of the gage region coincided with the peak load. Final fracture occurs shortly after the onset of localization as shown in Figure 6 for both materials. 


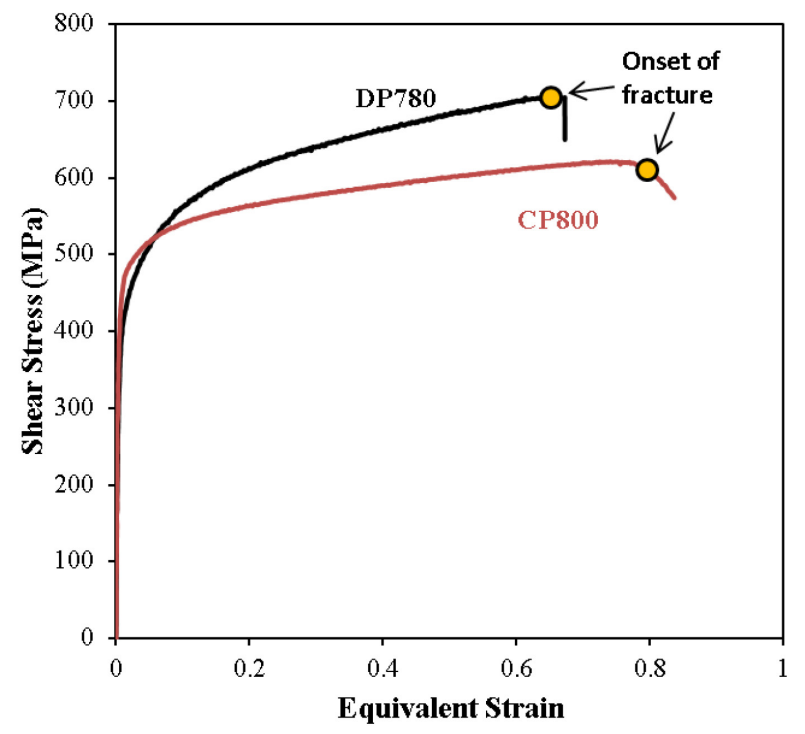

Figure 6: Comparison of the average shear stress with the local von Mises equivalent strain for the DP780 and CP800 steel.

The onset of fracture is therefore taken as when the hardening rate becomes negative and respective von Mises equivalent strain for the CP800 and DP780 steels are $0.81 \pm 0.03$ and $0.65 \pm 0.03$. The final fracture strain is taken at the onset of visible cracking in the DIC and is somewhat subjective with values for the CP800 and DP780 of $0.87 \pm 0.04$ and $0.67 \pm 0.03$, respectively.

\subsection{Shear Angle and Microhardness Measurements on the In-Plane Shear Tests}

The gage region of the in-plane specimens was sectioned and mounted using a hot compression thermosetting resin followed by polishing to a diamond grit size of 0.25 microns and etched with $2 \%$ Nital to reveal grain boundaries under an optical microscope as shown in Figure 7. When subjected to a simple shear deformation the grains will re-orient where the angle of rotation is proportional to the strain. The micrograph in Figure 5 shows the rotation of grains where the initial orientation of the grains was parallel to the rolling direction. Using ImagePro analysis software, a line length of $0.2 \mathrm{~mm}$ was used to measure the orientation angle of the grains, $\alpha$, and defines the gage length of the shear strain measurements. This gage length was chosen to be consistent with the method of extracting the DIC strains where the strains are averaged within a diameter of $0.2 \mathrm{~mm}$. 

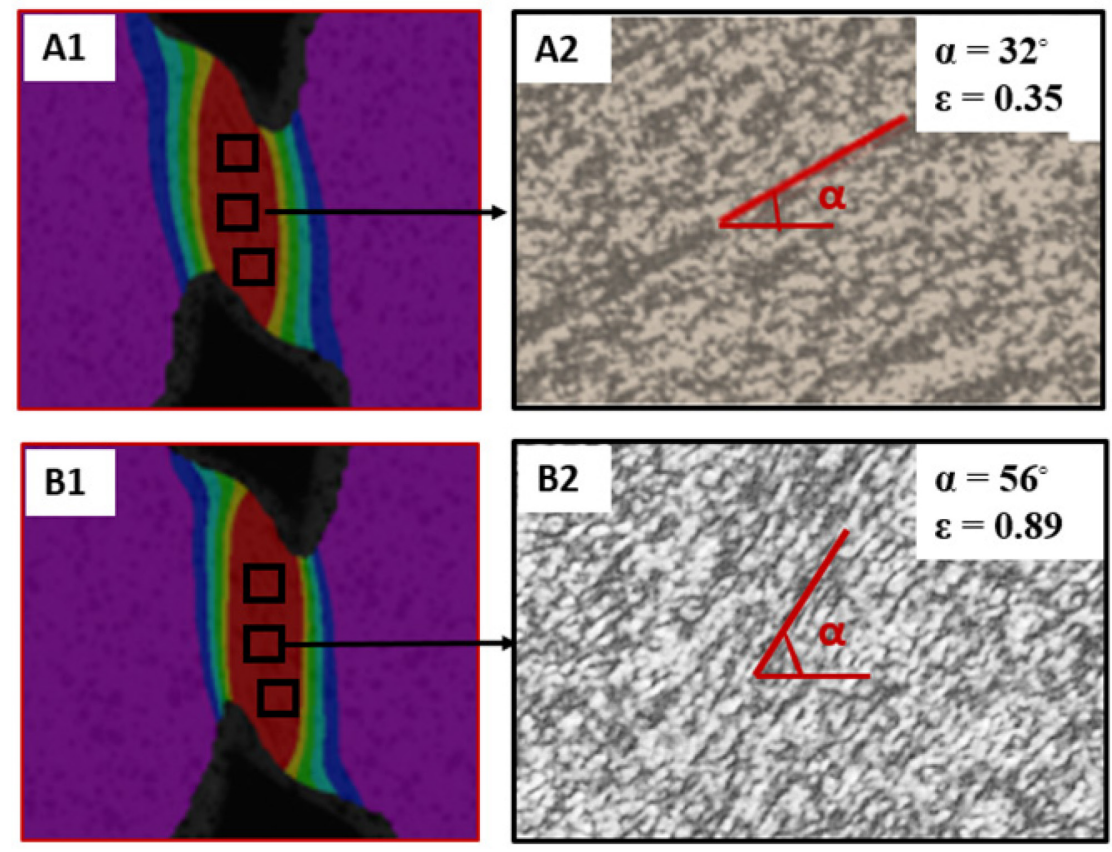

Figure 7: Strain contour plot of (a1) DP780 and (b1) CP800 shear specimen. Micrographs of the respective interrupted shear specimen indicating shear angle (a2) and (b2). Shear direction is vertical in the images.

The metallographic specimens were then re-polished to remove the etched surface so that microhardness measurements could be taken at the same locations as the grain angle measurements. Microhardness measurements were conducted using a Leitz pyramid microhardness tester using a $500 \mathrm{~g}$ indenter load. For each shear specimen three Vickers microhardness measurements were conducted within the shear zone and an average value obtained. In this manner the values of microhardness and shear angles are obtained for a known equivalent strain from the DIC and that correlations can be established to characterize the residual shear strain.

To correlate the shear angle and hardness measurements with strain, ten in-plane shear tests were performed. One specimen each was deformed to $5 \%, 15 \%, 30 \%$ and $50 \%$ of the average failure strain, while two specimens each were deformed to $70 \%, 85 \%$ and $95 \%$ of the failure strain. These strain levels were obtained by stopping the test at the pre-set cross-head displacement identified from the shear tests that were taken to fracture. The DIC strain measurements were extracted from three locations within the shear zone, as shown in Figure 4. The values reported are the von Mises equivalent strain averaged within a $0.2 \mathrm{~mm}$ diameter 
circle at each location. The measured data is given in Tables 2 and 3 for the DP780 and CP800 specimens, respectively, along with the shear angles and microhardness measurements.

Table 2: The average values of equivalent strain, shear angle and hardness of the DP780 interrupted shear specimens. The value in the brackets is the standard deviation after three measurements.

\begin{tabular}{|c|c|c|c|c|c|c|}
\hline $\begin{array}{c}\text { Sample } \\
\text { No. }\end{array}$ & $\begin{array}{c}\text { Equivalent } \\
\text { Strain }\end{array}$ & $\begin{array}{c}\text { Failure } \\
\text { Strain } \\
\text { Level }\end{array}$ & $\begin{array}{c}\text { Major } \\
\text { Strain }\end{array}$ & $\begin{array}{c}\text { Shear } \\
\text { Angle } \\
(\circ)\end{array}$ & $\begin{array}{c}\text { Cross-head } \\
\text { Displacement } \\
\text { (mm) }\end{array}$ & $\begin{array}{c}\text { Microhardness } \\
\text { (HV 500) }\end{array}$ \\
\hline 1 & $0.67(0.03)$ & 95 & $\begin{array}{c}0.56 \\
(0.03)\end{array}$ & $47(5)$ & 1.27 & $351(5)$ \\
\hline 2 & $0.66(0.04)$ & 95 & $\begin{array}{c}0.58 \\
(0.04)\end{array}$ & $48(4)$ & 1.27 & $358(4)$ \\
\hline 3 & $0.62(0.04)$ & 85 & $\begin{array}{c}0.52 \\
(0.04)\end{array}$ & $45(3)$ & 1.14 & $346(8)$ \\
\hline 4 & $0.61(0.04)$ & 85 & $\begin{array}{c}0.50 \\
(0.04)\end{array}$ & $44(4)$ & 1.14 & $343(3)$ \\
\hline 5 & $0.50(0.05)$ & 70 & $\begin{array}{c}0.42 \\
(0.05)\end{array}$ & $39(3)$ & 0.98 & $339(7)$ \\
\hline 6 & $0.47(0.03)$ & 70 & $\begin{array}{c}0.39 \\
(0.03)\end{array}$ & $37(4)$ & 0.95 & $340(5)$ \\
\hline 7 & $0.36(0.03)$ & 50 & $\begin{array}{c}0.28 \\
(0.03)\end{array}$ & $29(3)$ & 0.73 & $325(7)$ \\
\hline 8 & $0.20(0.03)$ & 30 & $\begin{array}{c}0.20 \\
(0.03)\end{array}$ & $22(2)$ & 0.48 & $300(3)$ \\
\hline 9 & $0.11(0.04)$ & 15 & $\begin{array}{c}0.09 \\
(0.04)\end{array}$ & $10(3)$ & 0.30 & $282(4)$ \\
\hline 10 & $0.05(0.03)$ & 7.5 & $\begin{array}{c}0.03 \\
(0.03)\end{array}$ & $4(3)$ & 0.17 & $257(6)$ \\
\hline
\end{tabular}

Table 2: The average values of equivalent strain, shear angle and hardness of the CP800 interrupted shear specimens. The value in the brackets is the standard deviation of three measurements.

\begin{tabular}{|c|c|c|c|c|c|c|}
\hline $\begin{array}{c}\text { Sample } \\
\text { No. }\end{array}$ & $\begin{array}{c}\text { Equivalent } \\
\text { Strain }\end{array}$ & $\begin{array}{c}\text { \%o of } \\
\text { Failure } \\
\text { Strain } \\
\text { Level }\end{array}$ & $\begin{array}{c}\text { Major } \\
\text { Strain }\end{array}$ & $\begin{array}{c}\text { Shear } \\
\text { Angle } \\
(\circ)\end{array}$ & $\begin{array}{c}\text { Cross-head } \\
\text { Displacement } \\
(\mathbf{m m})\end{array}$ & $\begin{array}{c}\text { Microhardness } \\
\text { (HV 500) }\end{array}$ \\
\hline 1 & $0.82(0.04)$ & 95 & $\begin{array}{c}0.72 \\
(0.04)\end{array}$ & $55(5)$ & 1.44 & $373(11)$ \\
\hline 2 & $0.80(0.03)$ & 95 & $\begin{array}{c}0.71 \\
(0.03)\end{array}$ & $54(4)$ & 1.44 & $377(4)$ \\
\hline 3 & $0.68(0.04)$ & 85 & $\begin{array}{c}0.60 \\
(0.04)\end{array}$ & $48(5)$ & 1.28 & $370(5)$ \\
\hline 4 & $0.69(0.03)$ & 85 & $\begin{array}{c}0.61 \\
(0.03)\end{array}$ & $47(3)$ & 1.28 & $367(4)$ \\
\hline
\end{tabular}




\begin{tabular}{|c|c|c|c|c|c|c|}
\hline 5 & $0.61(0.05)$ & 70 & $\begin{array}{c}0.53 \\
(0.05)\end{array}$ & $44(3)$ & 1.16 & $359(3)$ \\
\hline 6 & $0.50(0.03)$ & 70 & $\begin{array}{c}0.44 \\
(0.03)\end{array}$ & $40(4)$ & 0.99 & $352(3)$ \\
\hline 7 & $0.39(0.02)$ & 50 & $\begin{array}{c}0.34 \\
(0.02)\end{array}$ & $32(3)$ & 0.81 & $345(5)$ \\
\hline 8 & $0.30(0.03)$ & 30 & $\begin{array}{c}0.26 \\
(0.03)\end{array}$ & $25(4)$ & 0.66 & $339(3)$ \\
\hline 9 & $0.11(0.04)$ & 15 & $\begin{array}{c}0.10 \\
(0.04)\end{array}$ & $10(3)$ & 0.31 & $304(2)$ \\
\hline 10 & $0.04(0.02)$ & 7.5 & $\begin{array}{c}0.04 \\
(0.02)\end{array}$ & $5(2)$ & 0.18 & $296(3)$ \\
\hline
\end{tabular}

\section{Correlating Shear Angle and Microhardness with Equivalent Strain}

\subsection{Relationship between the Shear Angle and Equivalent Strain}

An analytical approach is presented to convert the measured shear angles indicated in Tables 2 and 3 to an equivalent strain using finite strain theory. The material is assumed to be rigidplastic to simplify the analysis by neglecting the elastic strains. Simple shear deformation is a special case of plane stress and plane strain loading where the displacement field can be described as:

$$
x_{1}=X_{1}+\gamma * X_{2}, \quad x_{2}=X_{2}, \quad x_{3}=X_{3}
$$

with $\gamma=\tan \alpha$, and $x_{i}, X_{i}$ represent the respective coordinates of the initial and deformed configurations (Figure 8). The deformation gradient for simple shear is:

$$
\mathbf{F}=\left[\begin{array}{lll}
1 & \gamma & 0 \\
0 & 1 & 0 \\
0 & 0 & 1
\end{array}\right]
$$




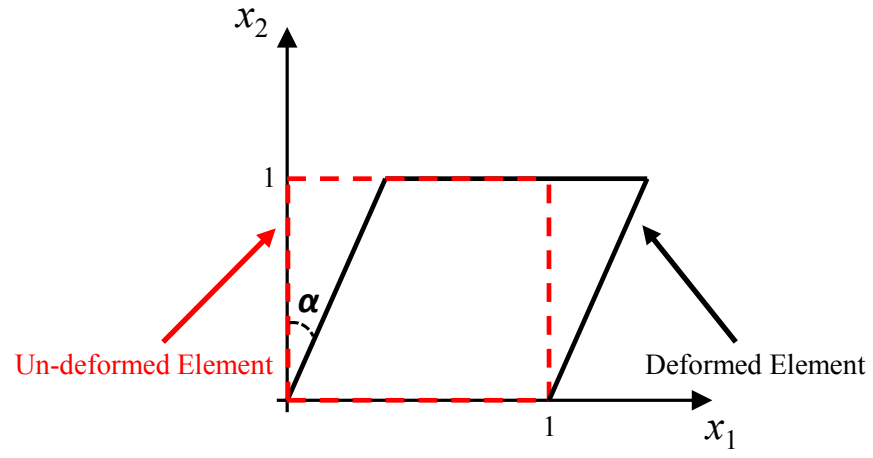

Figure 8: Simple shear deformation of a plane stress element

The Eulerian logarithmic strain tensor, $\varepsilon_{i j}$, has been derived by Zhou et al. (2003) as:

$$
\varepsilon_{i j}=\frac{\sinh ^{-1}(\gamma / 2)}{\sqrt{4+\gamma^{2}}}\left[\begin{array}{ccc}
\gamma & 2 & 0 \\
2 & -\gamma & 0 \\
0 & 0 & 0
\end{array}\right]
$$

The maximum shear strain for the strain tensor in Eq. (7) can be expressed as a function of $\gamma$ using:

$$
\varepsilon_{12}^{\max }=\varepsilon_{1}=\ln \left(\frac{\gamma}{2}+\sqrt{1+\frac{\gamma^{2}}{2}}\right)=\sinh ^{-1}\left(\frac{\gamma}{2}\right)
$$

The ordered principal strain components, $\varepsilon_{1-3}$, are:

$$
\begin{aligned}
\varepsilon_{1,3}= \pm \sinh ^{-1}(\gamma / 2) & = \pm \sinh ^{-1}\left(\tanh ^{-1}(\alpha)\right) \\
\varepsilon_{2} & =0
\end{aligned}
$$

For a rigid plastic material, no normal stress components develop. For elastic-plastic materials, the normal stresses only develop prior to yield and remain negligible relative to the shear stress (Rahmaan, et al., 2017), so the stress tensor is approximately

$$
\sigma_{i j}=\left[\begin{array}{ccc}
0 & \sigma_{12} & 0 \\
\sigma_{12} & 0 & 0 \\
0 & 0 & 0
\end{array}\right]
$$


Recently, for finite simple shear of a plastically deforming material, Butcher and Abedini (2017) derived the work-conjugate equivalent plastic strain that accounts for misalignment of the principal frames as a function of the major strain as

$$
\varepsilon_{e q}=2\left(\frac{\sigma_{12}}{\sigma_{e q}}\right) \sinh \varepsilon_{1}
$$

For the von Mises yield criterion, this work-conjugate equivalent strain becomes

$$
\varepsilon_{e q}=\frac{2}{\sqrt{3}} \sinh \varepsilon_{1}
$$

However, it is important to note that the equivalent strain definition within the DIC software (Vic-7, Correlated Solutions Inc.) effectively uses the coaxial definition of the von Mises equivalent strain as

$$
\varepsilon_{\text {eq_coaxial }}=\underset{\sqrt{3}}{2} \varepsilon_{1}
$$

Eq. (14) is consistent with the solution of Onaka (2012) and is only approximately workconjugate at major strain levels lower than 50\%. Otherwise the solution of Butcher and Abedini (2017) in Eq. (13) must be used. For simple shear conditions, the finite strain calculation shown in Eq. (13) can be used to determine equivalent strain using shear angle measurements. The shear angles measured for the interrupted shear specimen (indicated in Table 2 and 3) were converted to a work-conjugate equivalent strain using Eq. (9) and Eq. (14) and is compared with the measured DIC strains, as shown in Figure 9. The DIC strains are in excellent agreement with the equivalent strain obtained using the finite strain conversion based on the measured shear angles with a respective $R^{2}$ of 0.94 and 0.96 for the DP780 and CP800. 

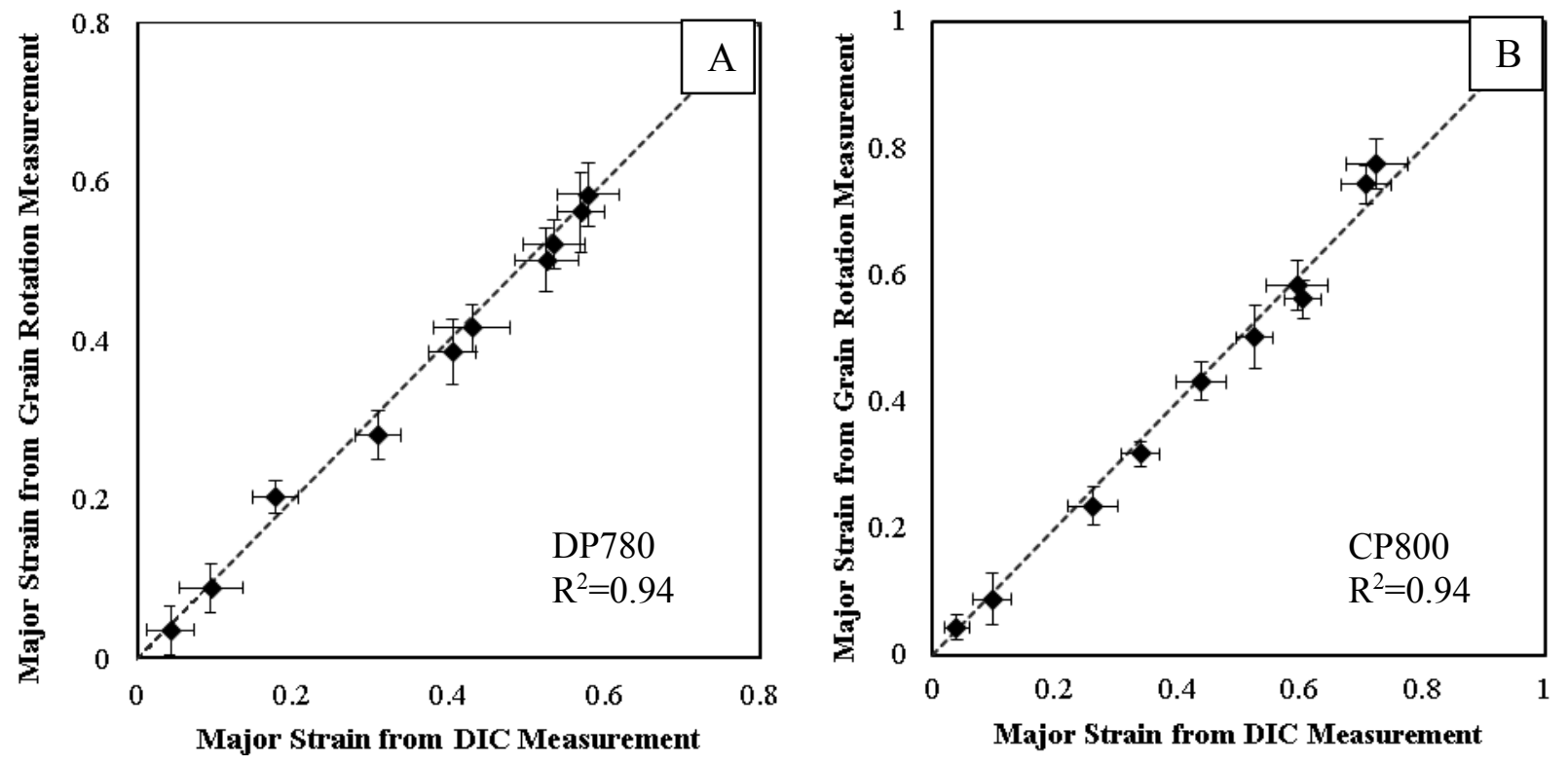

Figure 9: A comparison of major strain obtained from DIC analysis and grain rotation technique for the (A) DP780 and (B) CP800 steels using a gauge length of $0.2 \mathrm{~mm}$

\subsection{Correlation between the Microhardness and the Equivalent Strain}

A correlation can be established between the microhardness and the equivalent strain from the DIC using the data from Table 2 and 3. Since hardness is related to the work-hardening or yield stress, it is assumed that the hardening law of the materials can aid in developing the hardness correlation with the equivalent strain. The hardening model of Swift (1952) provides a reasonable approximation to these materials and is

$$
\sigma=k\left(\varepsilon_{o}+\varepsilon_{p}\right)^{n}
$$

where $k$ is the strength coefficient of a material, $n$ is a hardening exponent, $\varepsilon_{p}$ is the equivalent plastic strain and $\varepsilon_{o}$ is the elastic strain at yield. Figure 10 shows the measured true stress versus true strain for the CP800 and DP780 steels obtained from the tensile experiments. The Swift hardening parameters were identified for the two alloys and are indicated in Table 4.

Table 3: Swift power law parameters for the CP800 and DP780 steels

\begin{tabular}{|l|l|c|c|c|}
\hline Material & $K(\mathrm{MPa})$ & $n$ & $\varepsilon_{o}$ & $R^{2}$ \\
\hline CP800 & 1022 & 0.07 & 0.005 & 0.99 \\
\hline DP780 & 1261 & 0.16 & 0.004 & 0.96 \\
\hline
\end{tabular}




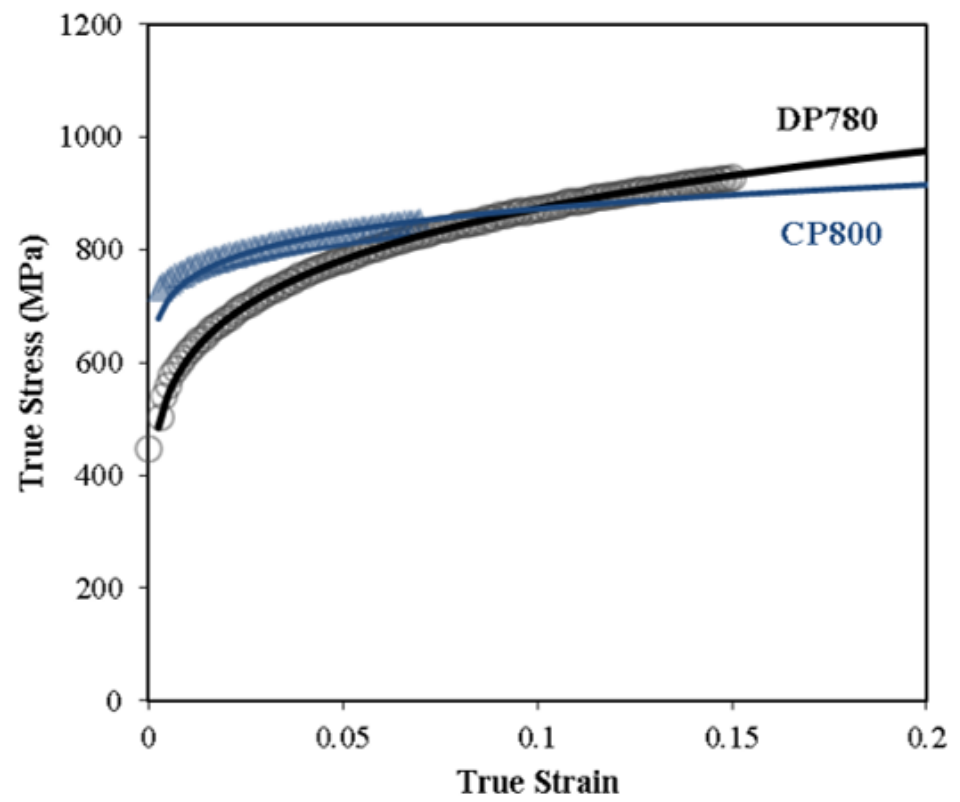

Figure 10: Comparison between experimental true stress versus true strain for the CP800 and DP780 steels and a Swift hardening model.

The power-law form of the Swift model in Eq. (15) can be re-cast in terms of two constants, $a$ and $b$, and the baseline hardness, $H V^{0}$, to solve for the equivalent plastic strain as

$$
\varepsilon_{e q}=\frac{1}{a}\left[\left(\frac{H V}{H V^{0}}\right)^{\frac{1}{b}}-1\right]
$$

in which $H V$ is the measured hardness. The equivalent strain from the DIC and the normalized hardness, $H V / H V^{0}$, for the interrupted tests are shown in Figure 11. The coefficients $a$ and $b$ are in Eq. (16) were obtained using a least-squares calibration for each material and are presented in Table 5. In general, the agreement between the fits and measured data is extremely good, as supported by the $R^{2}$ of value 0.98 and 0.99 for the CP800 and DP780 steels, respectively. Note that the assumption of a similar relationship between the equivalent strain and stress as well as the equivalent strain and hardness appears valid for the alloys considered in this work that have non-saturating hardening functions. Future work would be required to evaluate the proposed technique for materials such as aluminum alloys, for example, that exhibit saturating hardening behavior. 

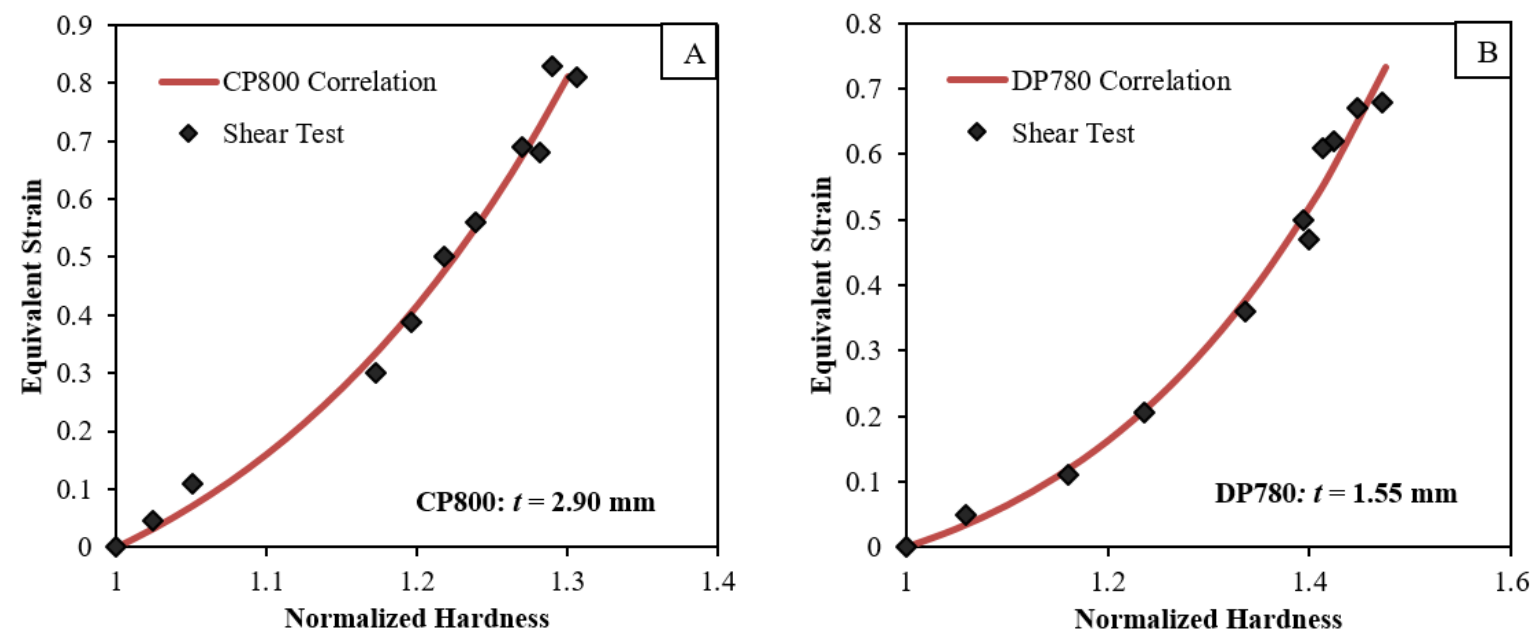

Figure 11: Variation in the equivalent strain with the normalized microhardness for (a) CP800 and (b) DP780 steel

Table 4: Parameters for the correlation between the microhardness and equivalent strain in shear loading.

\begin{tabular}{|c|c|c|c|c|}
\hline Material & $a$ & $b$ & $H V_{o}$ & $R^{2}$ \\
\hline CP800 & 4.9 & 0.16 & 289 & 0.98 \\
\hline DP780 & 11.4 & 0.17 & 243 & 0.99 \\
\hline
\end{tabular}

\subsection{Fracture Strains for In-Plane Shear Tests and Gage Length Effects}

In order to investigate the strain localization within a DP780 specimen, the equivalent strain from equally spaced points along the horizontal line-slice of length $2 \mathrm{~mm}$ (as shown in Figure 12) was extracted from the DIC image coinciding with the onset of localization.

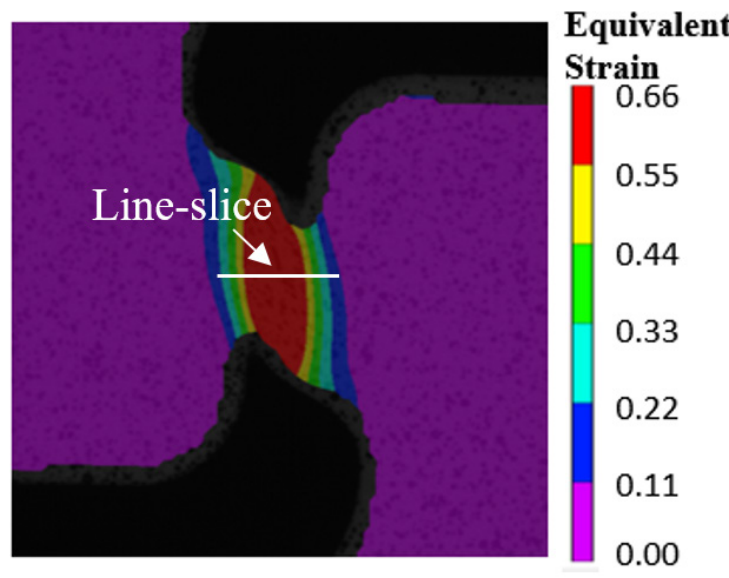

Figure 12: Line-slice shown across centre of the DP780 specimen prior to failure. 
In order to examine the proposed grain rotation measurement technique, measurements of shear strain were performed at the microstructural level based upon local grain rotation on the specimen interrupted near failure strain (Sample 1 indicated in Table 2). The shear angle was measured by drawing line of approximately $70 \mu \mathrm{m}$ length along rotated grains for roughly 30 locations across the shear band of the DP780 specimen interrupted near onset of the localization. Figure 13 shows two strain distributions across the shear band calculated from grain rotation measurement technique and extracted from the last DIC image of the specimen interrupted near failure. The two techniques are in close agreement with each other except near the center of localized band where the analytically calculated strain is higher than the DIC strain. This variation is due to difference in the length-scale between the microscopy and DIC techniques adapted for fracture characterization. The DIC analysis was performed using VSGL of $0.3 \mathrm{~mm}$ while the optical microscopy offered a resolution of $0.5 \mu \mathrm{m} /$ pixel and the grain rotation was measured using a line of length $70 \mu \mathrm{m}$. thus, the higher localized strains within the band are not captured with the DIC method due to lower resolution compared to the optical microscope. Therefore, the DIC strain measurement provides an underestimation of the analytically obtained strain within the localized shear band.

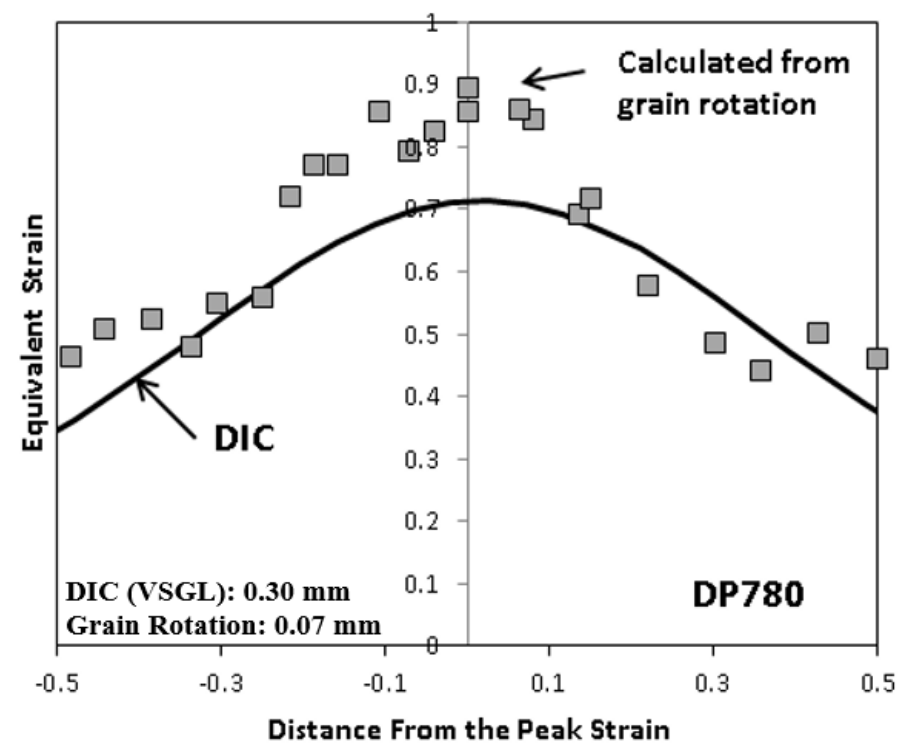

Figure 13: Distribution of the von Mises equivalent strains as a function of distance from the peak strain for DP780 using DIC and grain rotation measurement 
Recently, this technique was employed by Rahmaan et al. (2017) for shear tests at elevated strain rates using the same shear specimen geometry of Piers et al. (2012) for a DP600 steel. The shear angles due to grain rotations were measured on the fractured specimens and exhibited sharper strain localization and higher peak strains at fracture near the center of localized band as opposed to the DIC measurements, similar to the current results. These differences become even more significant at elevated strain rates where local adiabatic heating results in the collapse of the macroscopic shear band into an intense micro-shear band with severe local straining. The importance of gauge length is critical in such analysis since the macroscopic DIC strain measurements suggest that the failure strain is decreasing with strain rate, which is essentially an artifact due to the DIC length-scale, whereas the grain rotation method can resolve the strains within the micro-shear band that had a width on the order of 200 microns.

\section{Residual Shear Strain Measurement in Sheared Edges}

\subsection{Sheared Edge Cracking of AHSS}

In shearing of sheet materials, simple shear deformation occurs through-thickness and capturing this deformation using digital image correlation (DIC) is challenging in a typical blanking press. Wang et al. (2015) utilized high resolution in situ microscopy to record deformation during the blanking process by designing a new apparatus allowing the sheared region to be observed by camera. As an alternative, in this work we apply the two residual strain techniques to determine the residual strain field post-mortem. The grain rotation technique only depends upon the measured shear angle within the SAZ and is derived directly from finite-strain theory independent of the material hardening response. This technique was validated using the in-plane shear tests and DIC strain measurements but it can be applied to the through-thickness strain field in the SAZ. However, the micro-hardness correlation with the equivalent strain was developed based upon the hardening response for in-plane shear, and the mechanical response may be different in through-thickness shearing. Application of the hardness correlation to the SAZ inherently assumes that work-hardening during in-plane shear is representative of the through-thickness response. This assumption is commonly used in constitutive modeling due to 
the experimental issues with obtaining through-thickness shear data of a thin sheet (Barlat et al., 1991), (Barlat et al., 2005).

The edge stretchability of the two materials investigated herein has been characterized by the authors in their previous work using the hole expansion test (Pathak, et al., 2016) and hole tension test (Pathak, et al., 2017). In those studies, two edge conditions were considered: reamed and sheared holes at $12 \%$ clearance. It is important to note that the failure strains obtained in the hole expansion and hole tension tests correspond to failure in uniaxial tensile loading and are shown in Figure 14 for each alloy and edge condition. The edge stretchability reported for the sheared hole is lower compared to the reamed hole for both the materials due to the presence of residual strain, work hardening and damage within the SAZ. For the reamed condition, minimal work-hardening exists at the hole edge and this condition can be considered as an "ideal hole". We postulate that the residual strain generated in the SAZ is an indicator of the reduction in edge formability during the shearing process. Burr size is also a common metric for indicating poor edge stretchability, wherein a burr generally corresponds to a large clearance or poor tool condition such that the SAZ likely contains a more severe residual strain field. The two independent measurement techniques presented in the previous section (based on grain rotation and local hardness) are applied here to measure the pre-existing strain behind the sheared edge.

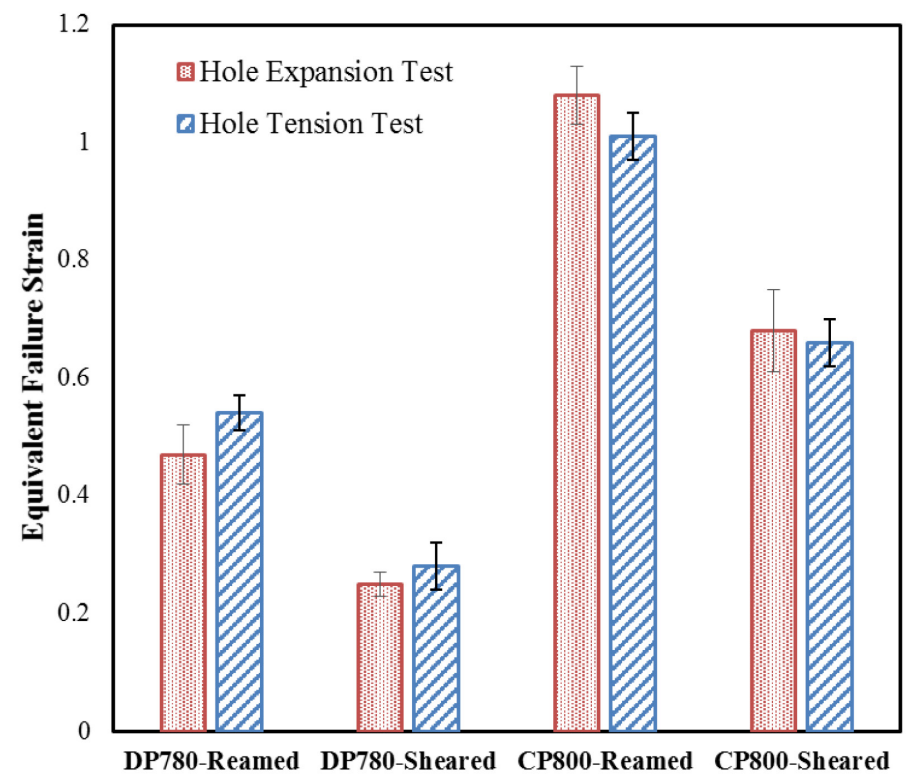

Figure 14: Equivalent failure strain for the DP780 and CP800 obtained during the hole tension and hole expansion tests for the reamed versus sheared edges (at 12\% clearance) (Pathak, et al., 2017) 


\subsection{Shear Angle and Hardness Measurements behind Sheared Edge}

A $10 \mathrm{~mm}$ hole was punched using an 85 ton hydraulic press in accordance with the hole expansion testing standards (ISO-16630 (ISO/TS , 2009) and JFS-1001 (Japan Iron \& Steel Federation Standard, 1996)) and the same hole punching process outlined by Pathak et al. (2016). Punches of different diameters were used to obtain desired clearances of $12 \%$ and $28 \%$ of thickness for the CP800 and DP780 steels. The sheared edges were sectioned and mounted along both the rolling and transverse directions and a set of two specimens was prepared for each material and condition. The mounted specimens were polished and etched using $2 \%$ Nital to reveal grain rotation as indicated in Figure 15 and 16. To measure the shear angle at a location, a line of approximate length $20 \mu \mathrm{m}$ was drawn along rotated grain boundaries using an image processing software (Imagepro). A coordinate system is defined across the SAZ with $X$ axis along the depth of the SAZ at the bottom surface and $Y$ axis along the limit of the sheared edge. Approximately 2000 lines (grain boundary orientations) aligned with the grains were manually measured behind the DP780 sheared edge and 4000 line measurements were conducted behind the CP800 sheared edges to record the shear angle and position (in terms of $X$ and $Y$ coordinates) across the SAZ. Since the thickness for the DP780 alloy is almost half the CP800 thickness, 2000 lines were drawn to cover the DP780 SAZ, instead of 4000. The limit of the SAZ was taken as the region in which the measured shear angle becomes close to zero. 

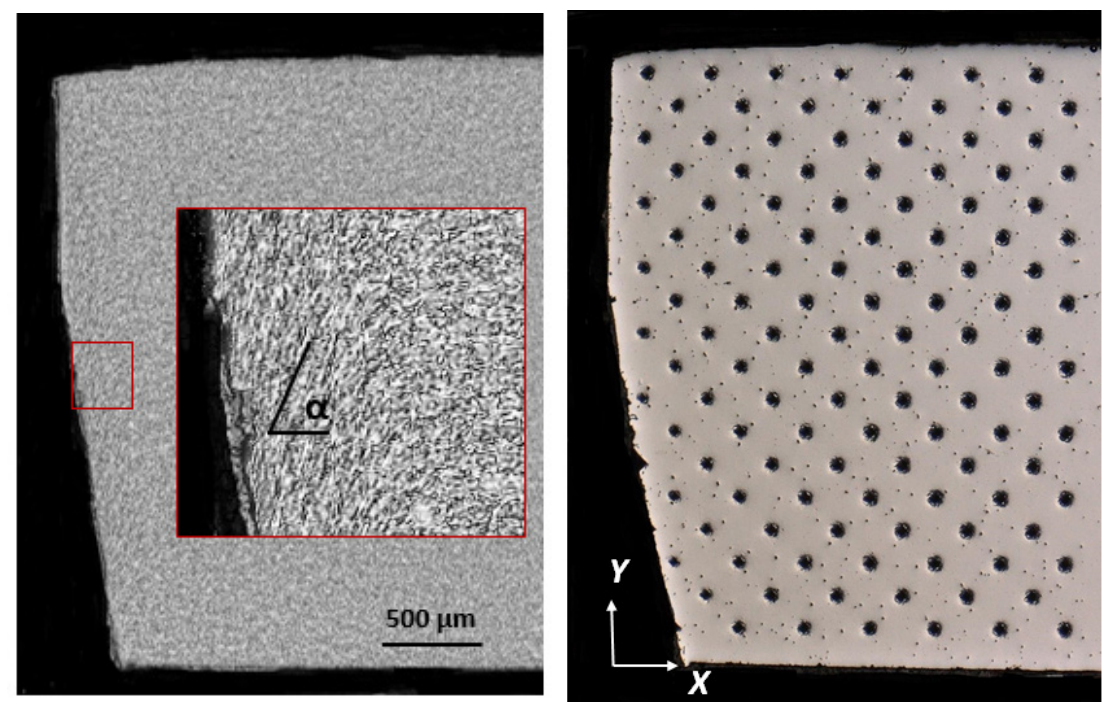

Figure 15: Sheared edge of CP800 at indicating hardness mapping (right) and Nital etch to highlight grain rotation (left). A 12\% punch clearance was used to shear a hole of $10 \mathrm{~mm}$ nominal diameter.
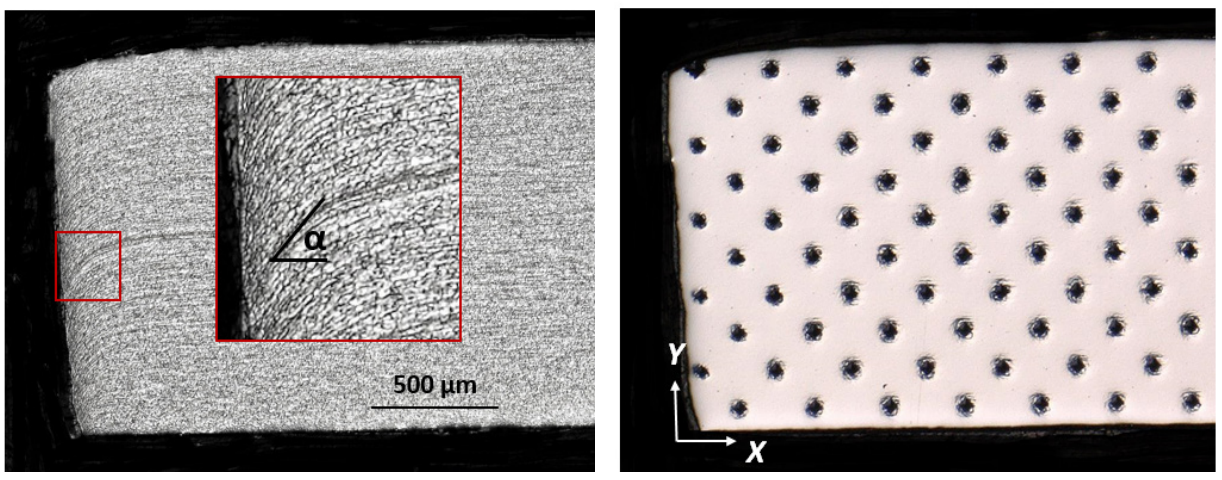

Figure 16: Sheared edge of DP780 indicating hardness mapping (right) and Nital etch to highlight grain rotation (left). A 12\% punch clearance was used to shear a hole of $10 \mathrm{~mm}$ nominal diameter.

Microhardness measurements were then taken on the sheared edge and the indentations were made in the form of an interlocking grid covering the SAZ as shown in Figure 15 and 16. A distance of approximately two indentations $(200 \mu \mathrm{m})$ was maintained between each hardness measurement to avoid interaction of the deformation fields surrounding each indent. Compared with the grain rotation technique, the effective gage length using the hardness tests is $200 \mu \mathrm{m}$, or ten times larger. For each indentation, the $X$ and $Y$ coordinates of the centroid of the indentation were recorded along with the hardness measurement in order to develop hardness distributions in the same reference system as for the shear angle measurements.

\subsection{Strain Measurement within the SAZ: Grain Rotation Technique}


Figure 17 shows the shear angle distribution within the SAZ of a CP800 sample sheared along the rolling direction with $12 \%$ die clearance. The colors in the scatter plot indicate the measured shear angle for that point. The distance from the sheared edge for a data point was calculated by subtracting the $X$ coordinate of a point from the location on the sheared face which lies at the same $Y$ coordinate as the data point, as illustrated in the micrograph in Figure 17.
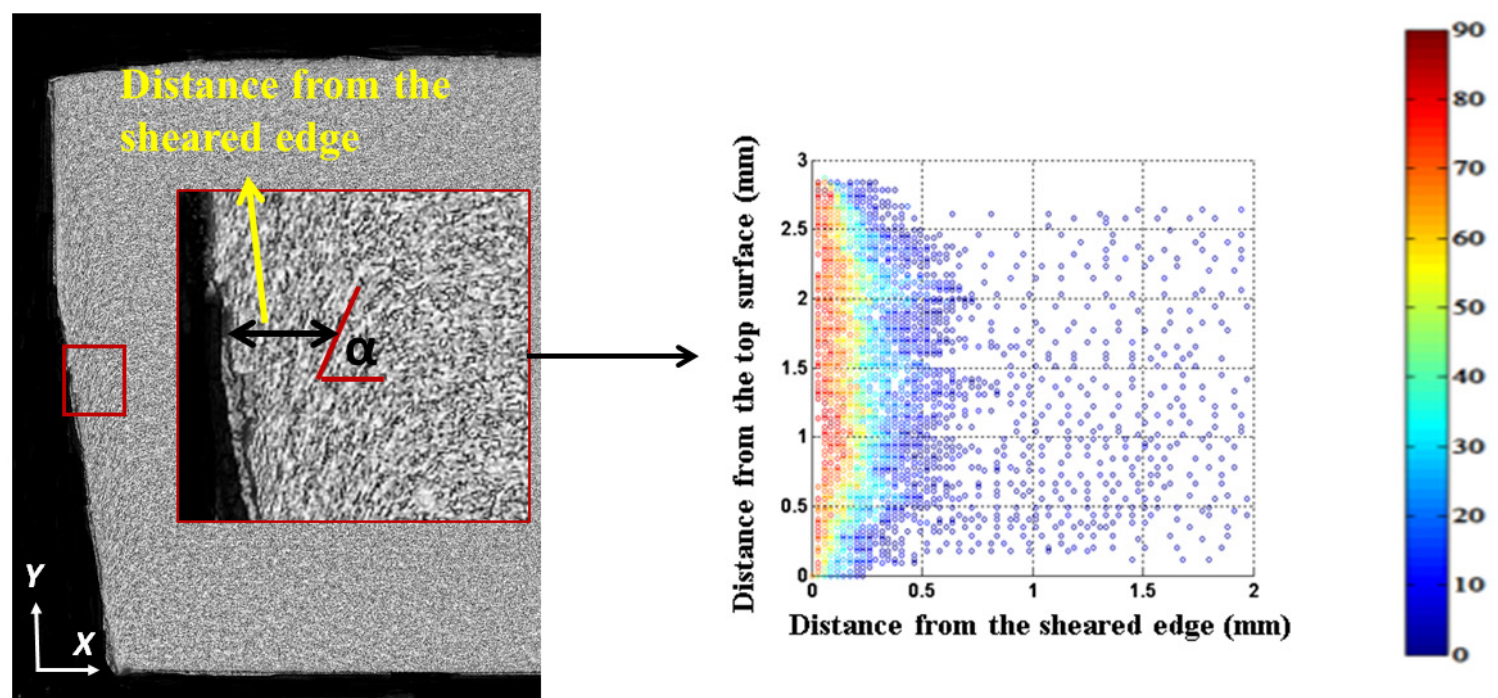

Figure 17: Illustration of shear angle measurement and position behind the sheared edge (left) and corresponding plot of shear angle (colors) versus position (right) for a CP800 sample sheared with 12\% die clearance. Each point corresponds to the shear angle determined for a line with a length of $20 \mu \mathrm{m}$.

Figure 18c and 19c show the corresponding shear angle spatial distributions for the CP800 and DP780 samples sheared along the rolling direction (12\% die clearance), while Figure 18a and 19a show elevation plots of the same data set. On considering the shear angle spatial distributions, it is apparent that the shear angle variation with distance from the specimen top surface (or edge) is relatively small away from the specimen surfaces, whereas a strong gradient exists with respect to distance from the sheared edge. The shear angle is the highest near the edge, decreases and becomes zero as it reaches the end of the SAZ, as shown in Figure 18b and 19b. Both alloys exhibited similar spatial variation of the measured shear angle, while similar trends were observed for the shear angle measurements conducted along the transverse direction for the two steels. 


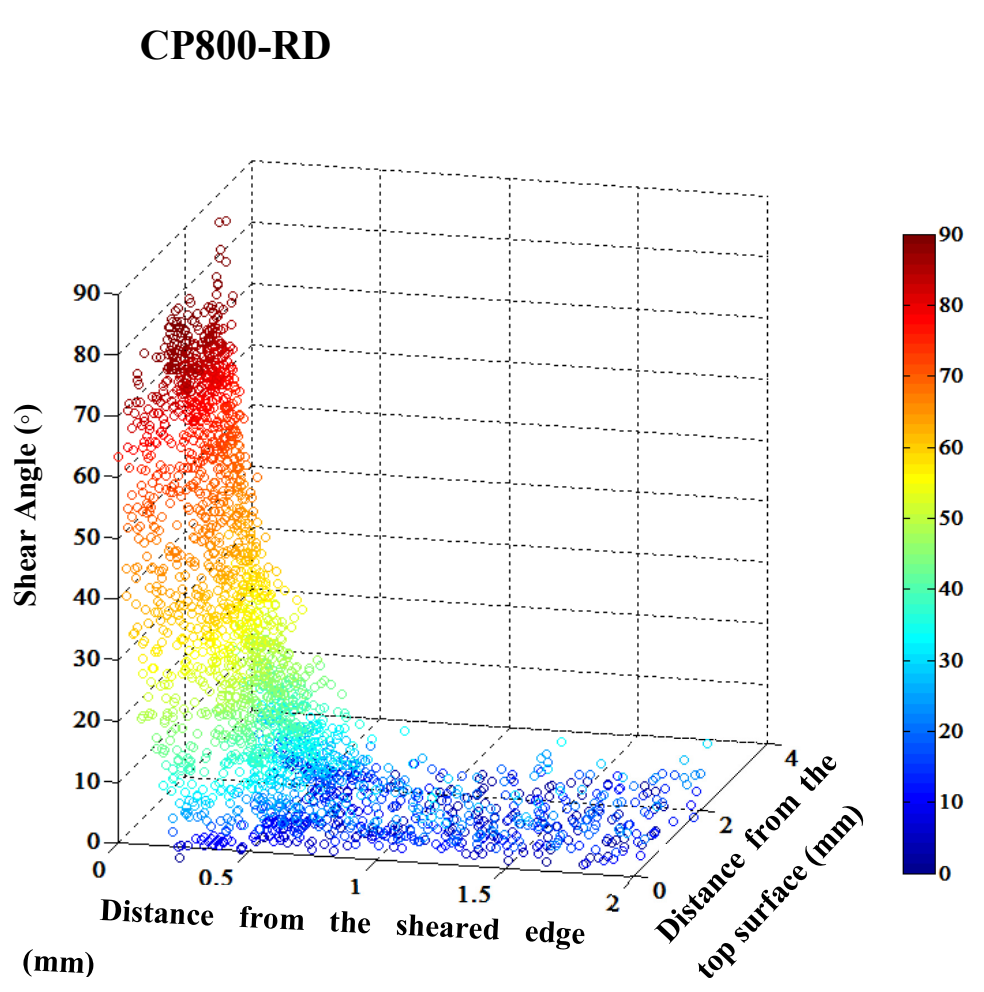

(a)

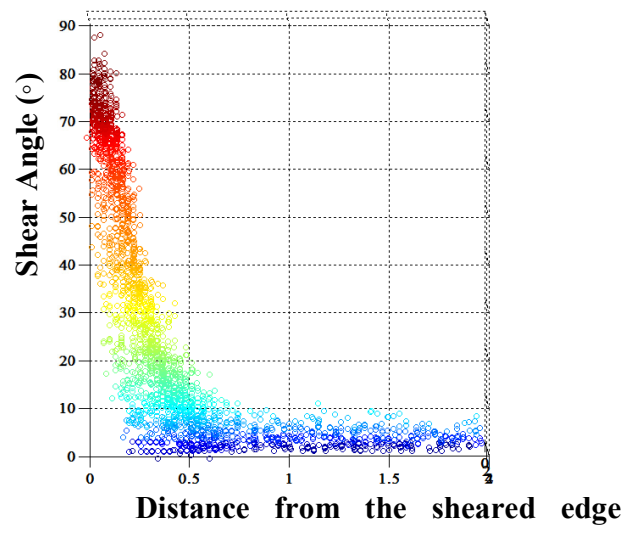

(b)

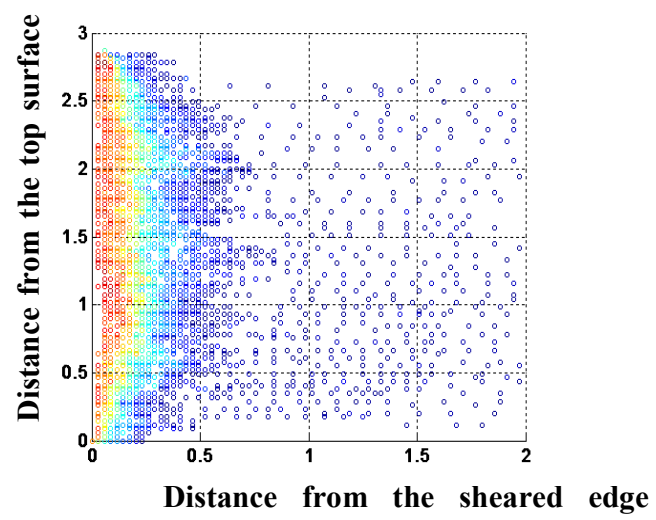

(c)

Figure 18: The shear angle profile for the CP800 rolling direction as a function of distance from the sheared edge and top edge. 


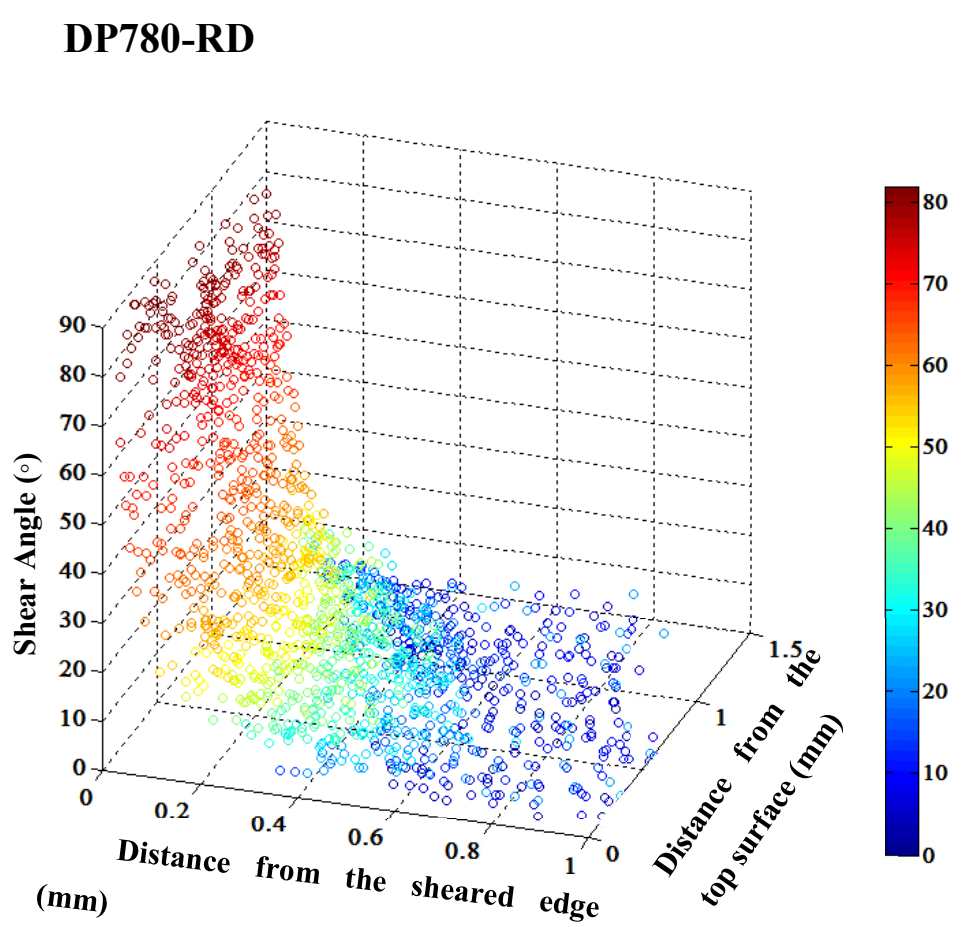

(a)

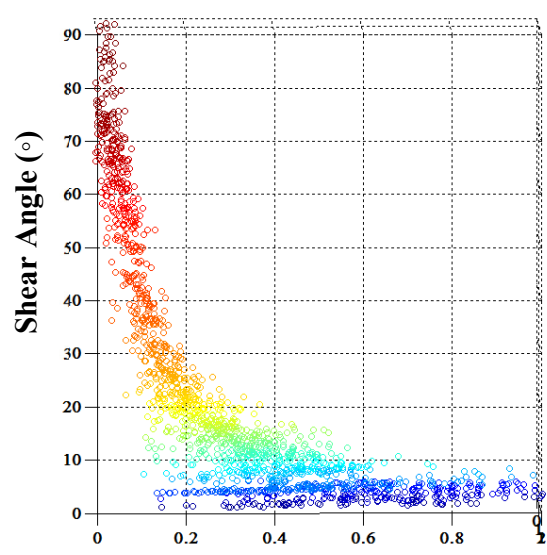

Distance from the sheared edge $(\mathrm{mm})$

(b)

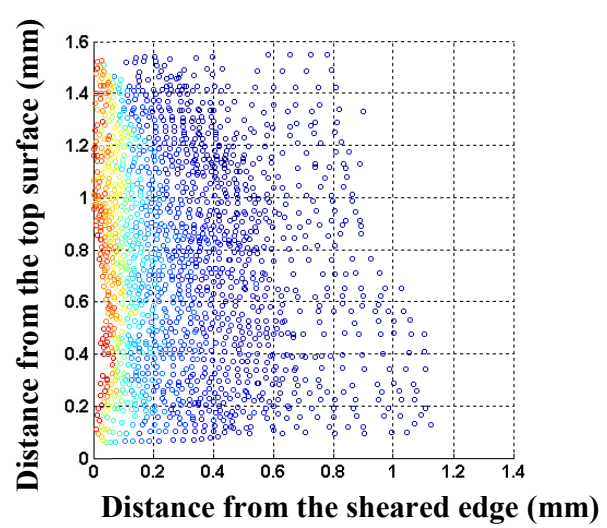

(c)

Figure 19: The shear angle profile for the DP780 rolling direction as a function of distance from the sheared edge and top edge.

By using Eq. (13), the measured shear angle distribution within the SAZ (indicated in Figures 18 and 19) can be converted to an equivalent strain. The strain distribution over the SAZ for the CP and DP sheared edges at 12\% clearance is shown in Figure 20 along the rolling and transverse orientations. The highest strain is observed at the edge and decreases away from the edge until it reaches the base material and becomes constant. 


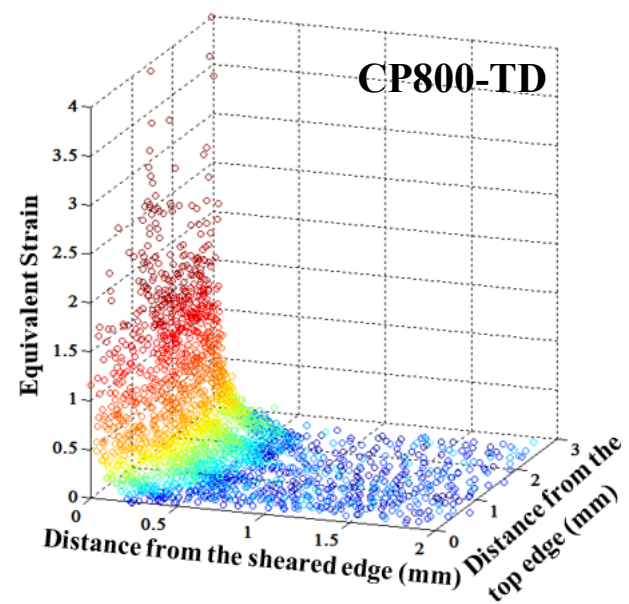

(a)

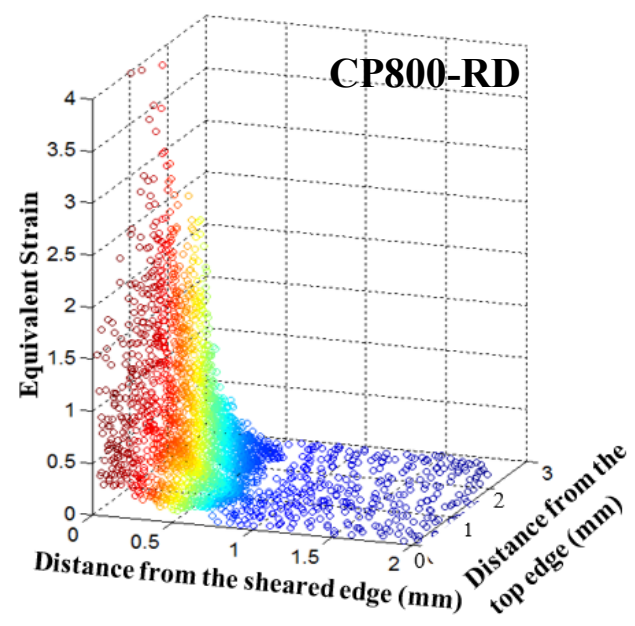

(c)

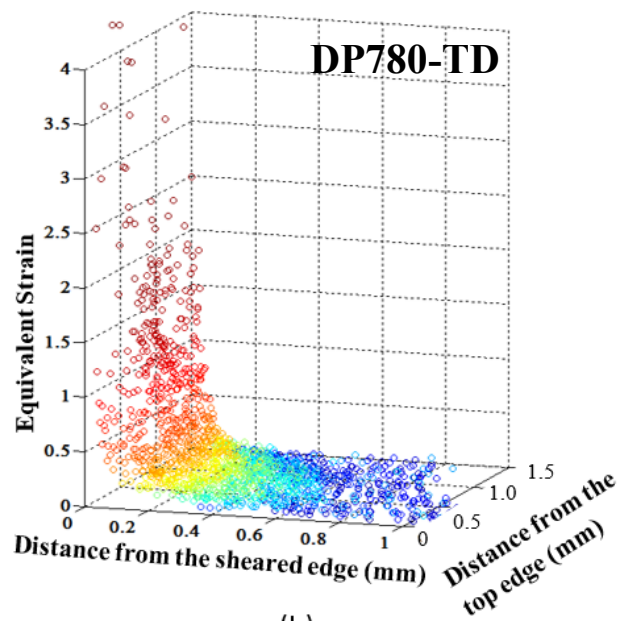

(b)

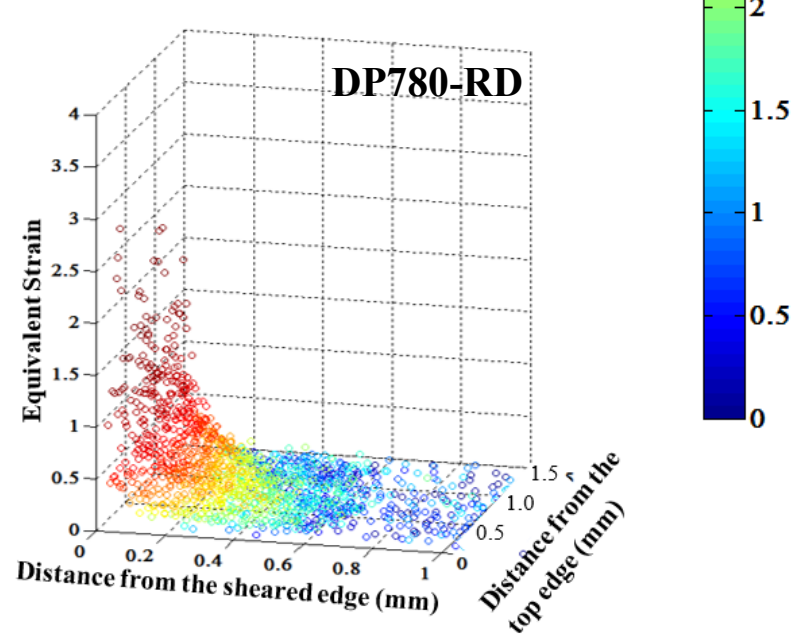

(d)

Figure 20: Strain distribution as a function of distance from the sheared edge and top edge for the (a) CP800 rolling, (b) DP780 rolling, (c) CP800 transverse and (d) DP780 transverse directions.

To compare strain distributions between the rolling and transverse directions, line slices through the shear strain distributions were extracted along the $X$-direction for each material at four $Y$ coordinates, corresponding to $33 \%, 50 \%, 66 \%$ and $75 \%$ of the sheet thickness $(1.0,1.5$, 2.0, and $2.5 \mathrm{~mm}$ from the top edge, respectively, for the CP800 sheared edges and 0.3, 0.6, 0.9 and $1.2 \mathrm{~mm}$ for the DP780. Figure 21 and 22 presents the strain-distributions for the CP800 and DP780 steels respectively. The strain distributions for the rolling- and transverse-oriented sheared samples are in close agreement with each other for both the materials. From a modeling 
point-of-view, this observation is important since the strain-distribution behind the sheared edge can assumed to be similar in all directions for the materials considered in this study.

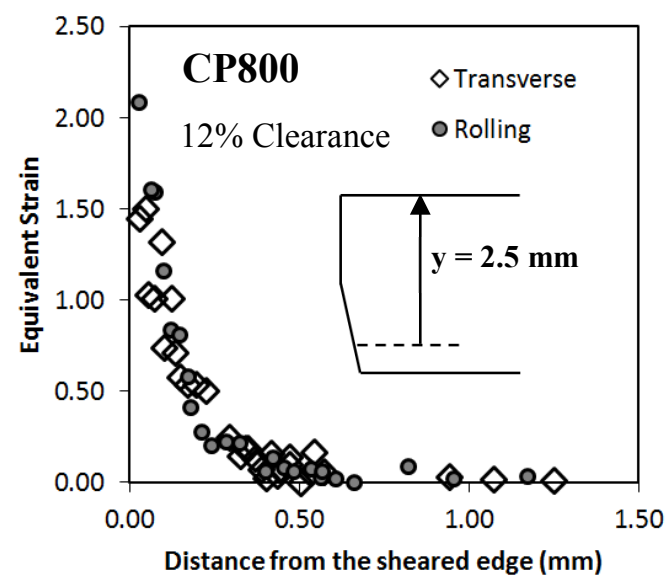

(a)

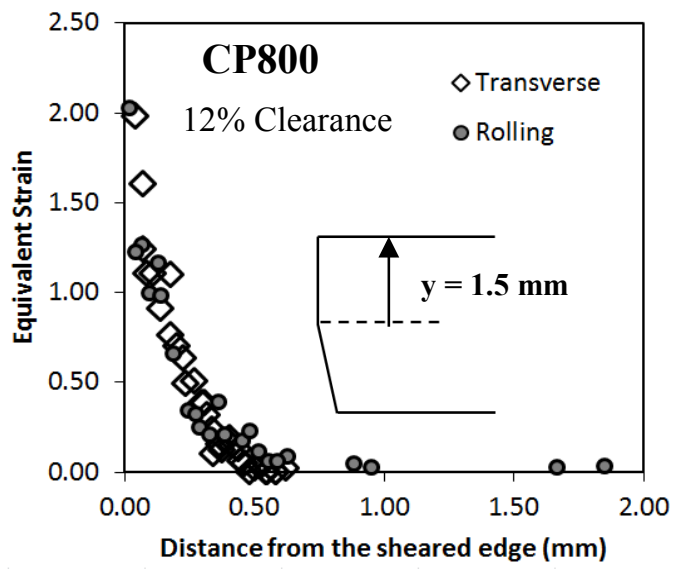

(c)

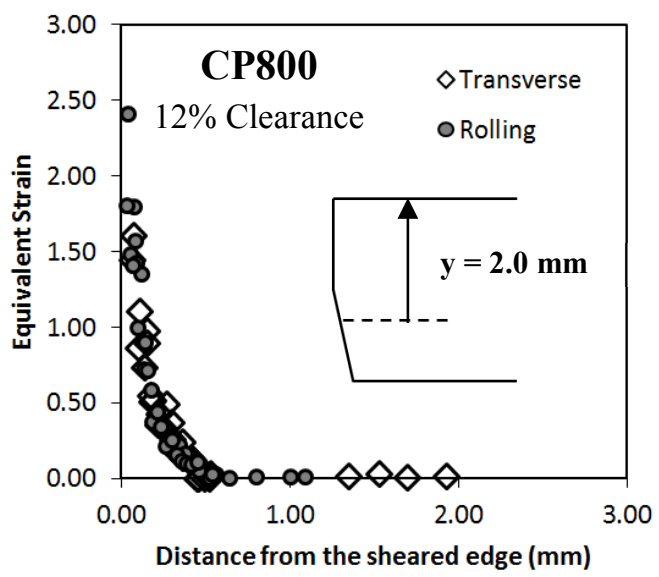

(b)

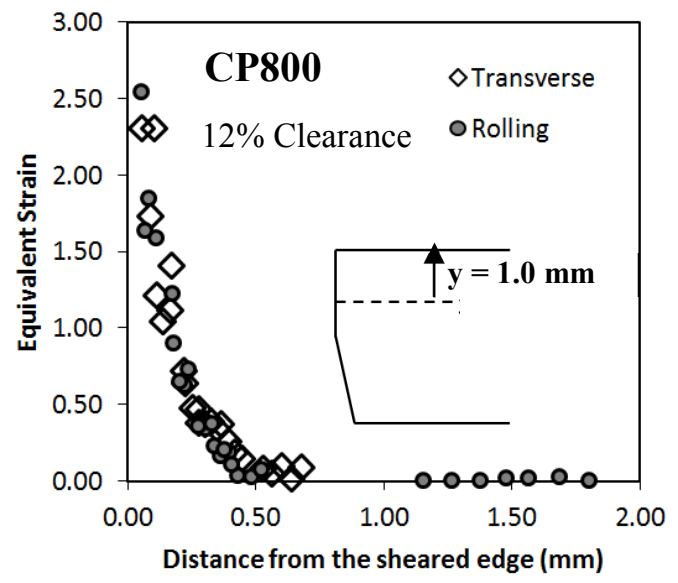

(d)

Figure 21: Comparison of strain-distribution for the CP800 steel along the rolling and transverse directions at various distances from the top edge: (a) $y=2.5 \mathrm{~mm}$, (b) $y=2.0 \mathrm{~mm}$, (c) $y=1.5$, (d) $y=1.0 \mathrm{~mm}$. A $12 \%$ punch clearance was used to shear a hole of diameter $10 \mathrm{~mm}$. 


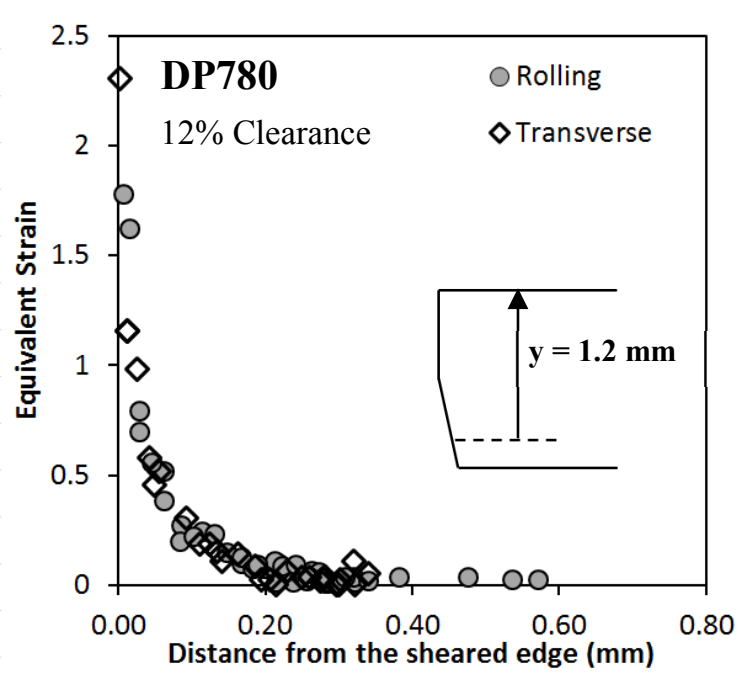

(a)

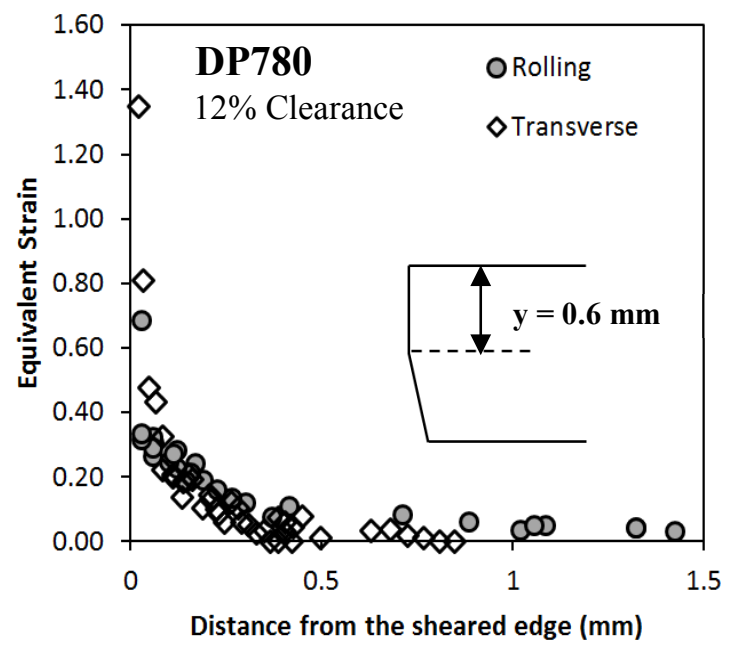

(c)

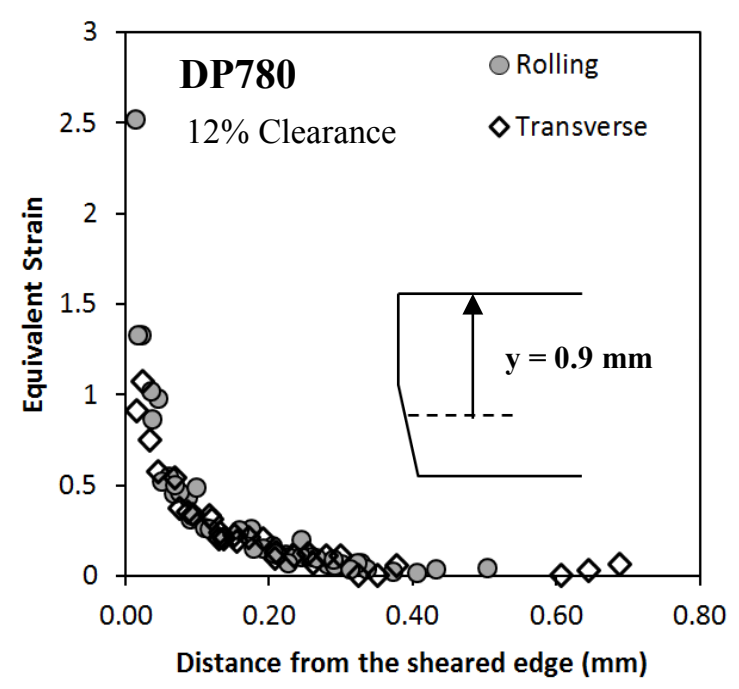

(b)

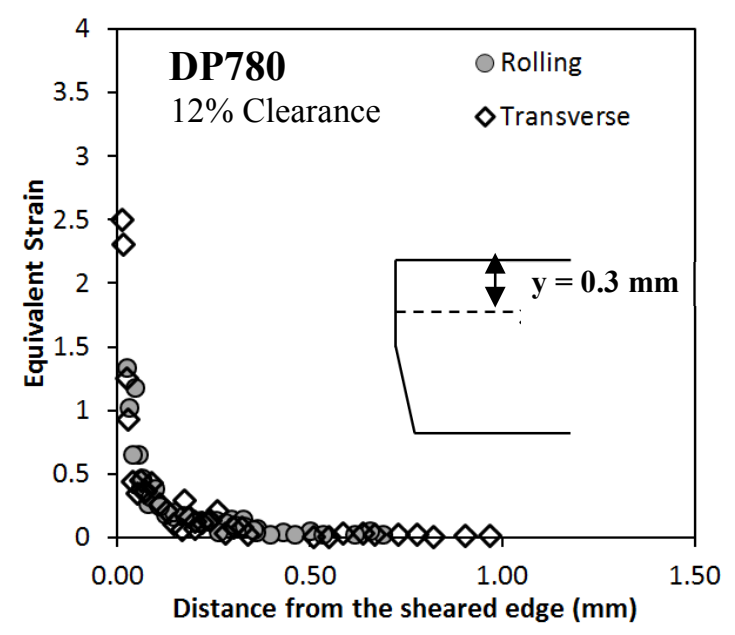

(d)

Figure 22: Comparison of strain-distribution for the DP780 steel along the rolling and transverse directions at various distances from the top edge (a) $y=1.2 \mathrm{~mm}$, (b) $y=0.9 \mathrm{~mm}$, (c) $y=0.6 \mathrm{~mm}$, (d) $y=0.3 \mathrm{~mm}$. A $12 \%$ punch clearance was used to shear a hole of diameter $10 \mathrm{~mm}$.

\subsection{Strain Measurement within the SAZ: Hardness-Based Technique}

The hardness distributions as a function of distance from the CP800 and DP780 edges, sheared at $12 \%$ clearance and sectioned along the rolling direction, are presented in Figure 23 . These hardness measurements were taken from the very same edge where the shear angles were measured (see Figure 17 and 18). The distance from the sheared edge for an indentation was calculated with respect to the point on the shear face which lies at the same Y coordinate as the indentation. The indentations located at a distance from the sheared edge less than twice the size of the indenter do not meet the spacing requirements (Herrmann, 2011) for this technique and 
were excluded. Each point on the figure represents a measurement from an indentation. Similar trends were observed for the hardness distributions along the transverse direction for the two materials.

It is important to note that the principal stress directions in the in-plane shear tests are aligned in the rolling and transverse directions and have the same magnitude where one is in tension and the other is compression. Assuming that the DP780 and CP800 have negligible tension-compression asymmetry, the shear response will be the same for simple shear whether the major principal strain is in the RD or TD. Consequently, the microhardness correlation of Eq. (16) obtained for these tests can be applied to differentiate the accumulated strain in the RD and TD within the SAZ with assumption that the through-thickness shear response is similar to the in-plane shear tests.

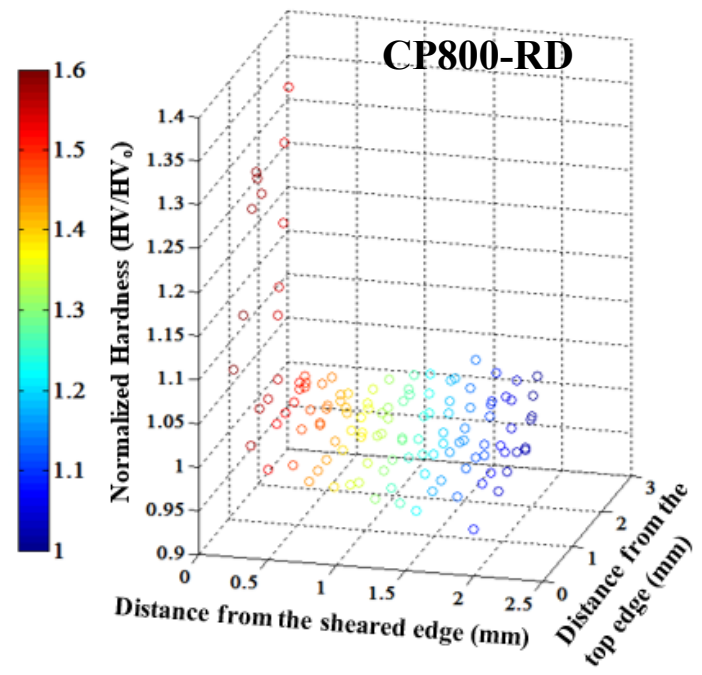

(a)

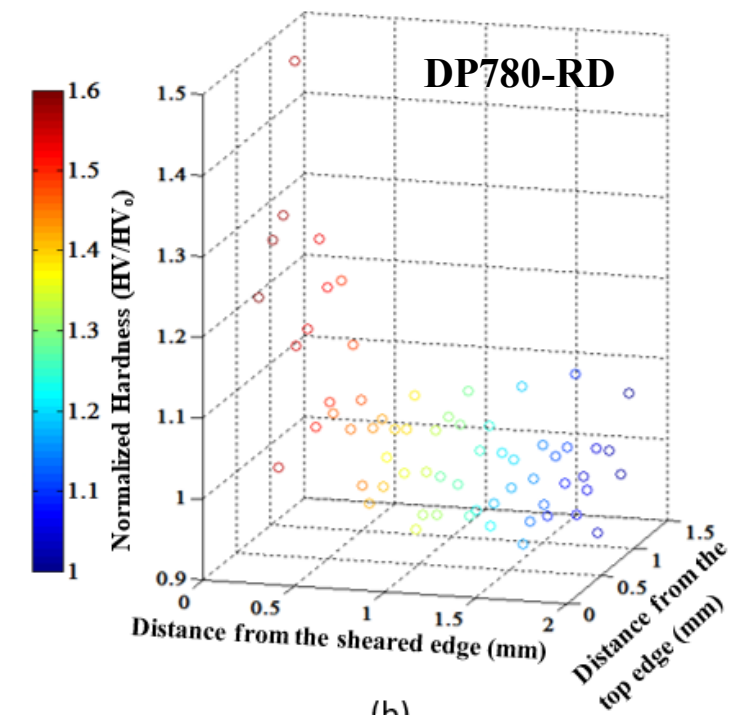

(b)

Figure 23: The normalized hardness profile for the (a) CP800 and (b) DP780 rolling directions as a function of distance from the sheared edge and top edge.

The hardness distributions of the CP800 and DP780 along the rolling and transverse orientations were converted to equivalent strain using the hardness correlation for the in-plane shear tests of Eq. (16). The resulting strain distributions are shown in Figure 24. Similar to the strain-distribution obtained from grain rotation measurement technique, higher strains are observed at the edge, with a sharp decrease away from the sheared edge. 

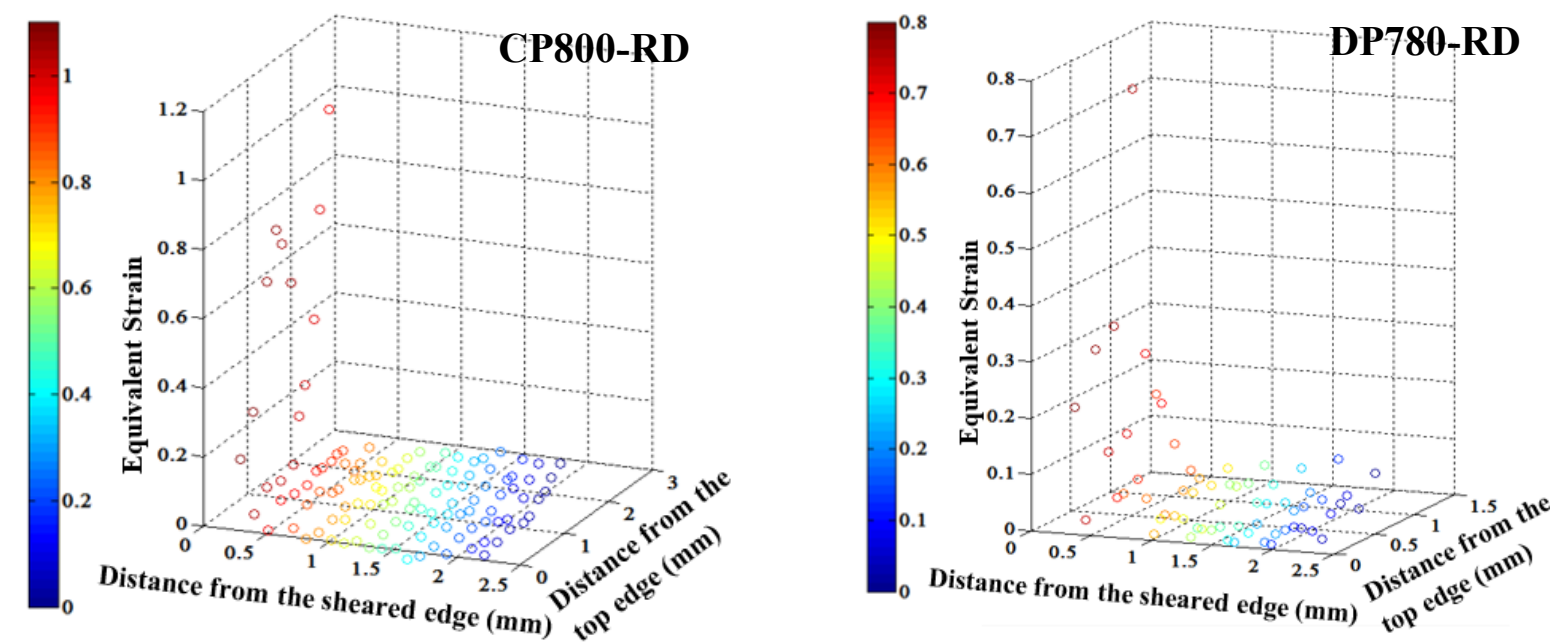

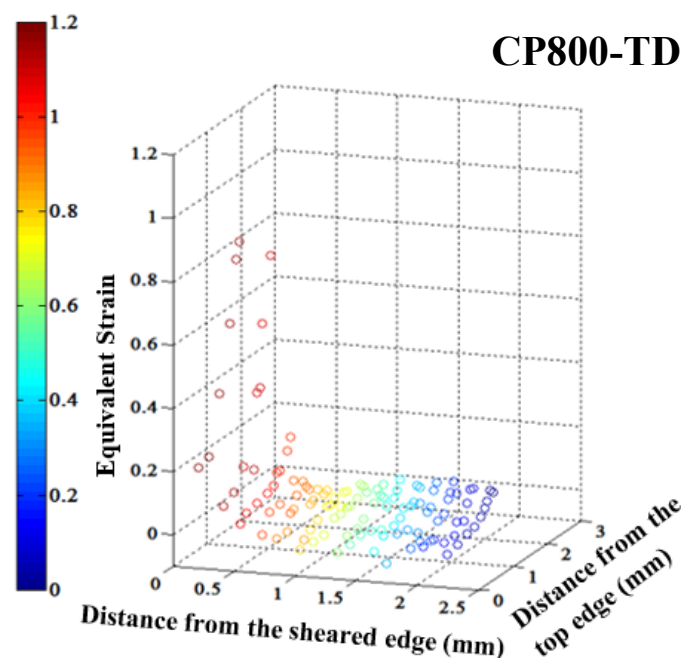

(c)
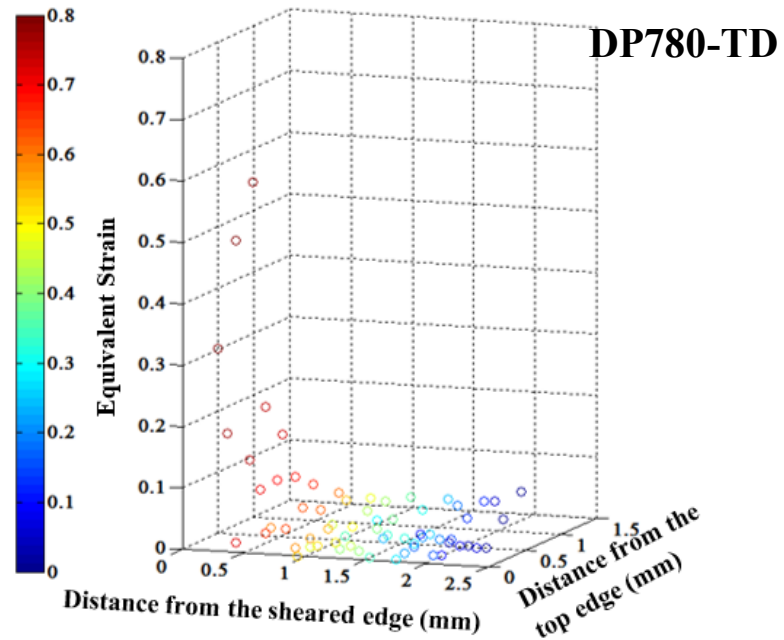

(d)

Figure 24: Strain distribution as a function of distance from the sheared edge and top edge for the (a) CP800 rolling, (b) DP780 rolling, (c) CP800 transverse and (d) DP780 transverse directions.

To evaluate the assumption of isotropic strain-distribution in all the directions for the hardness measurement technique, the line slices were extracted from strain-distribution obtained along the rolling and transverse directions at four $Y$ positions that corresponds to $33 \%, 50 \%, 66 \%$ and $75 \%$ of the sheet thickness. As shown in Figure 25 and 26, the difference between the straindistributions along the two directions was not significant for both the materials, except at $Y=0.03$ $\mathrm{mm}$. Therefore, the residual strain distribution in the SAZ for the punched hole can be envisaged as axisymmetric and only vary in the radial direction if it was to be input into a finite-element forming simulation to predict edge cracking. 


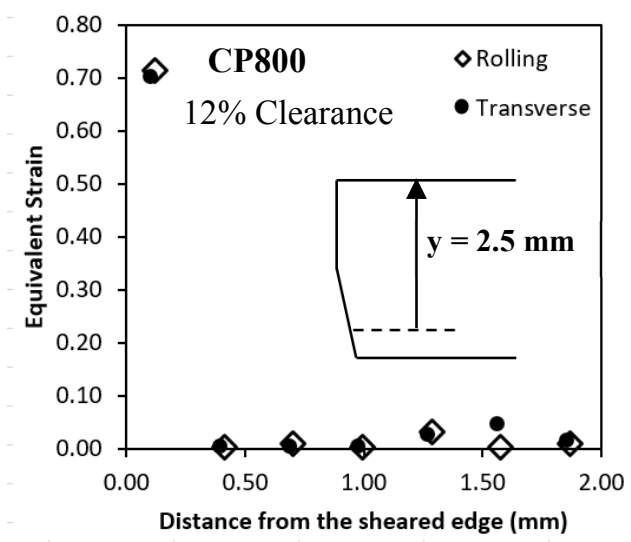

(a)

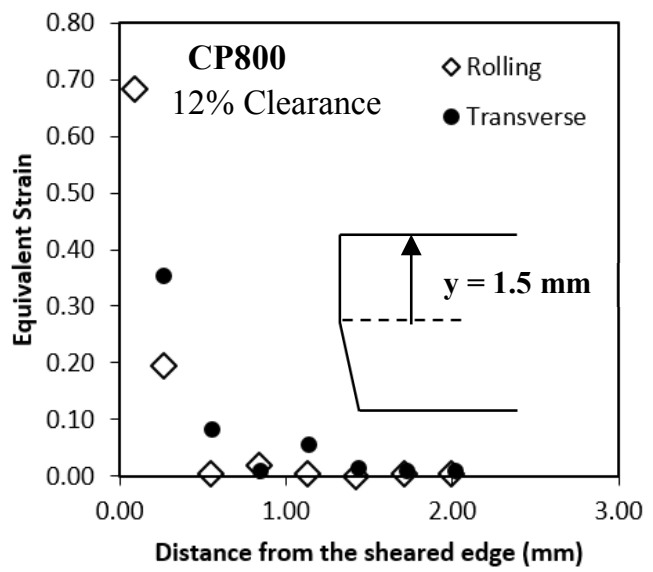

(c)

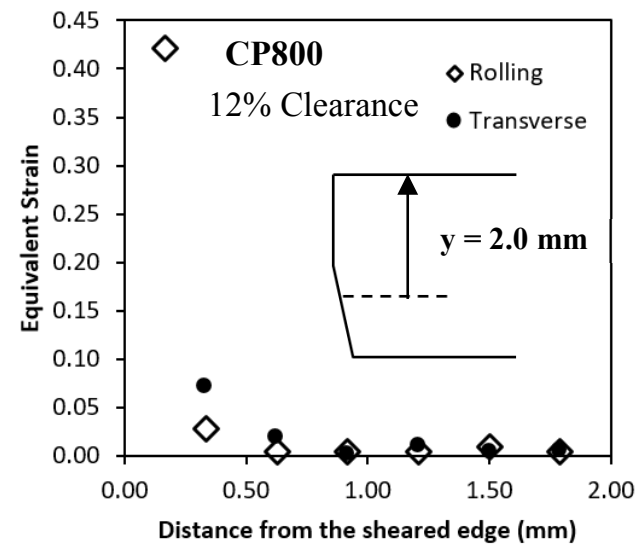

(b)

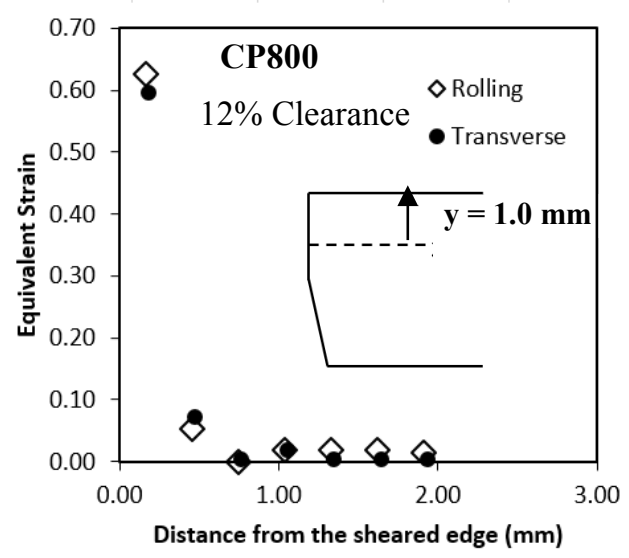

(d)

Figure 25: The comparison of strain-distribution for the CP800 steel along the rolling and transverse directions at (a) $y=2.5$ $\mathrm{mm}$, (b) $y=2.0 \mathrm{~mm}$, (c) $y=1.5$, (d) $y=1.0 \mathrm{~mm}$. A 12\% punch clearance was used to shear a hole of diameter $10 \mathrm{~mm}$. 


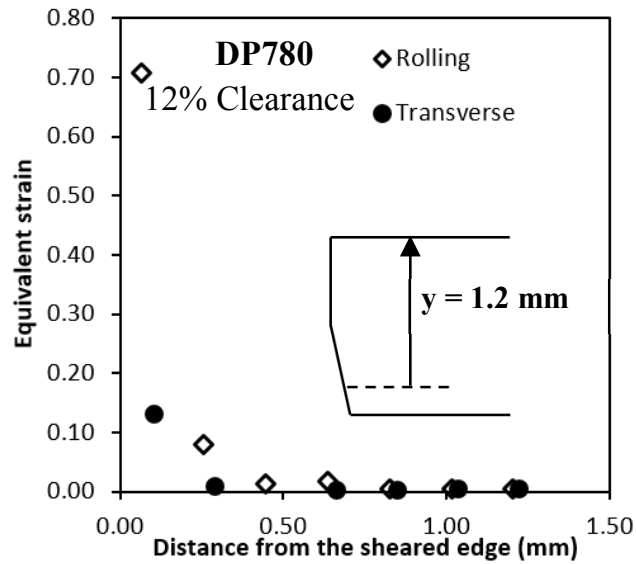

(a)

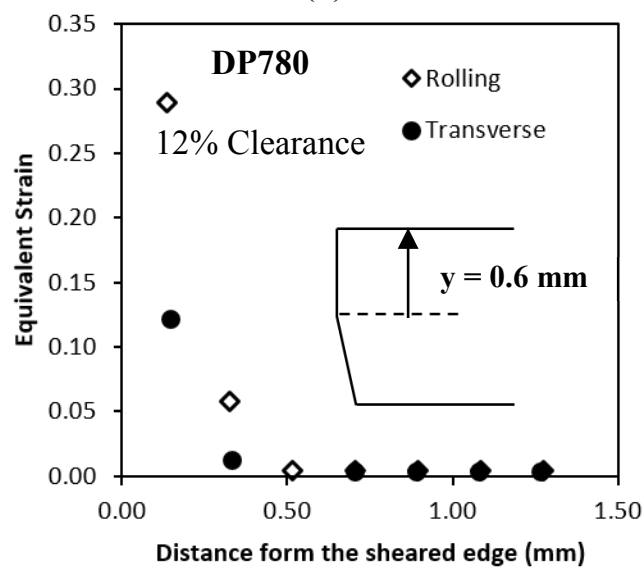

(c)

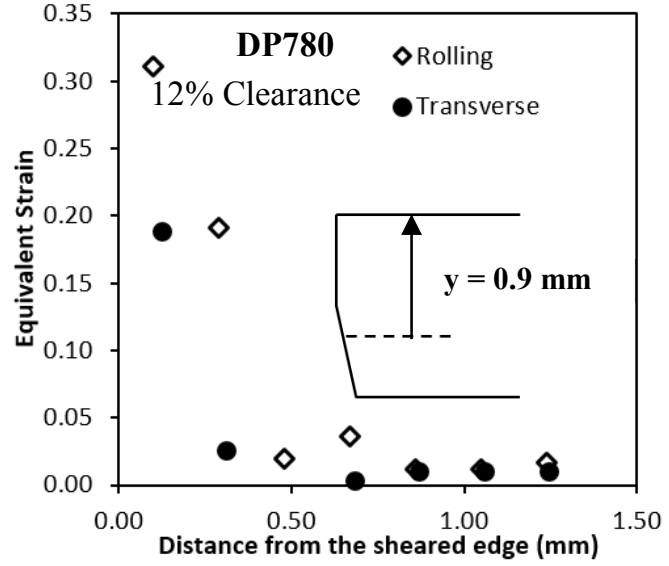

(b)

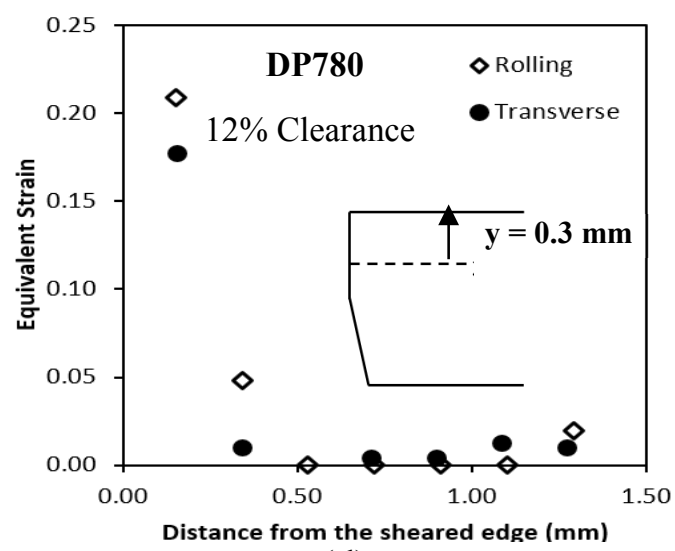

(d)

Figure 26: The comparison of strain-distribution for the DP780 steel along the rolling and transverse directions at (a) $y=1.2 \mathrm{~mm}$, (b) $y=0.9 \mathrm{~mm}$, (c) $y=0.6$, (d) $y=0.3 \mathrm{~mm}$. A $12 \%$ punch clearance was used to shear a hole of diameter $10 \mathrm{~mm}$.

\subsection{Comparison between Grain Rotation and Hardness Measurement Techniques}

To evaluate the influence of anisotropy on the through-thickness shear response compared to in-plane shear, the equivalent strains obtained using the hardness correlation in the SAZ can be compared with the strains obtained from grain rotations, assuming the though-thickness of the sheet can be approximated as homogeneous simple shear behind the fracture surface. Despite these assumptions, a comparison of the two strain measurement techniques in Figures 27 and 28 for various depths through the thickness are in fairly good agreement for both materials. 


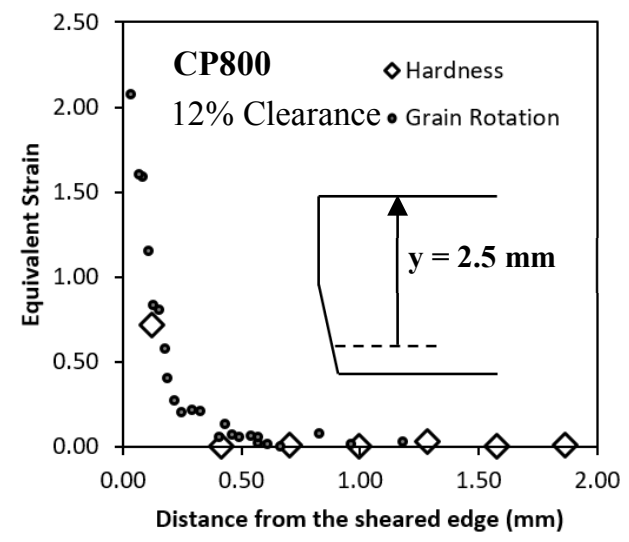

(a)

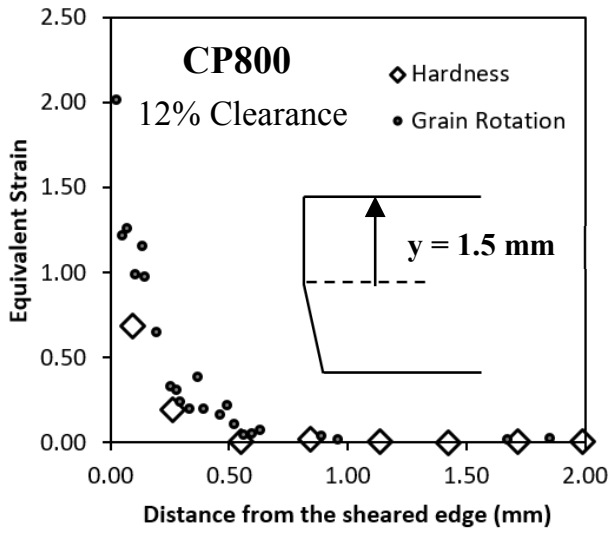

(c)

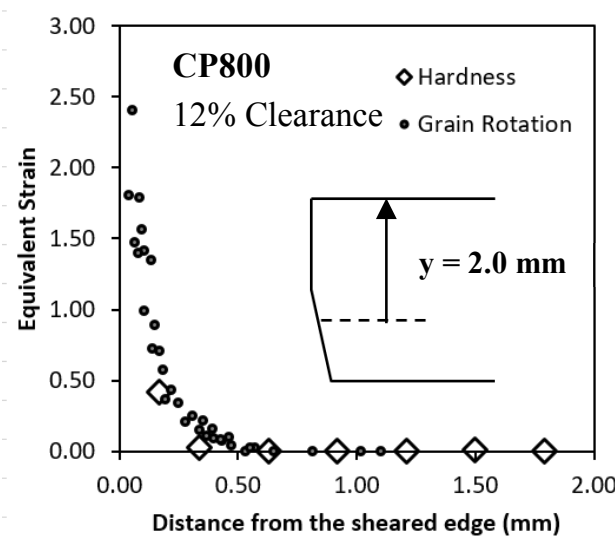

(b)

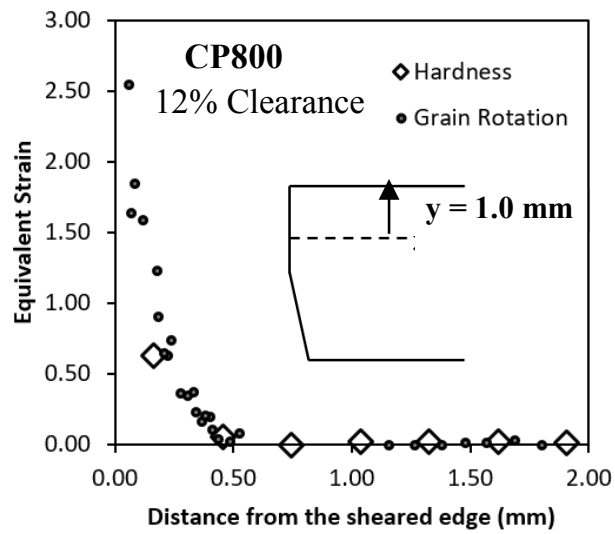

(d)

Figure 27: The comparison between the strain-distributions derived from the grain rotation and hardness measurement techniques for the CP800 at: (a) $y=2.5 \mathrm{~mm}$, (b) $y=2.0 \mathrm{~mm}$, (c) $y=1.5$, (d) $y=1.0 \mathrm{~mm}$. A $12 \%$ punch clearance was used to shear a hole of diameter $10 \mathrm{~mm}$.

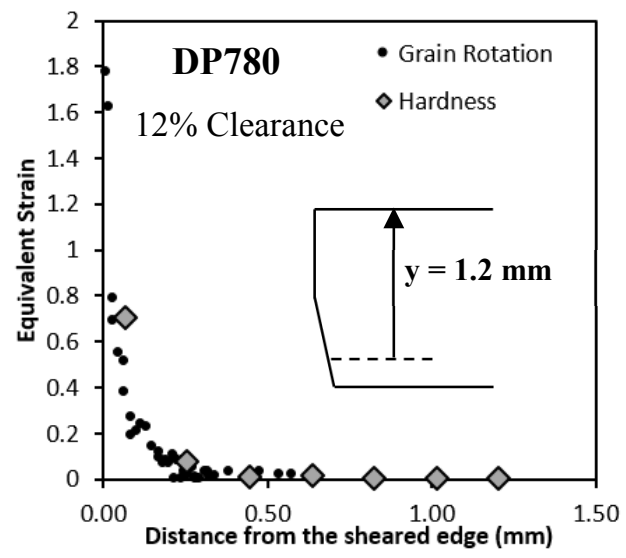

(a)

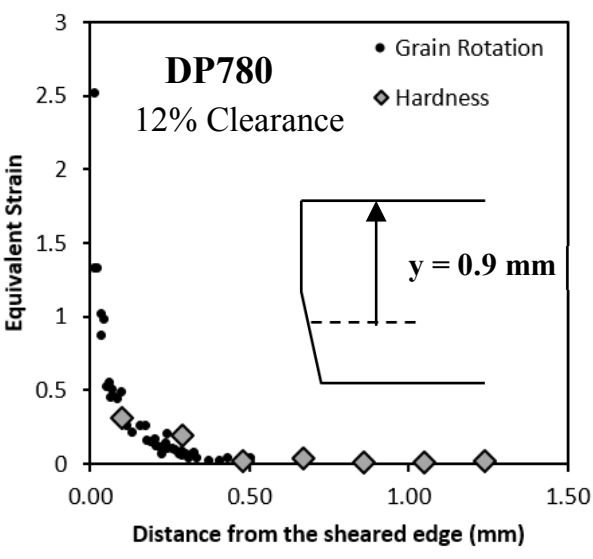

(b) 


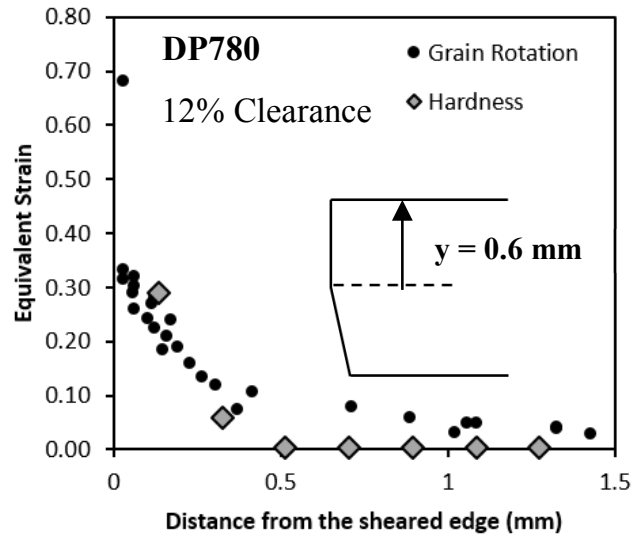

(c)

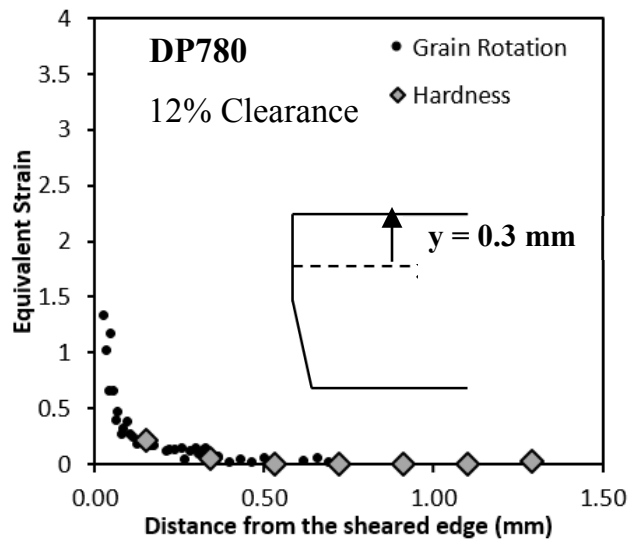

(d)

Figure 28: The comparison between the strain-distributions derived from the grain rotation and hardness measurement techniques for the DP780 at: (a) $y=1.2 \mathrm{~mm}$, (b) $y=0.9 \mathrm{~mm}$, (c) $y=0.6 \mathrm{~mm}$, (d) $y=0.3 \mathrm{~mm}$. A 12\% punch clearance was used to shear a hole of diameter $10 \mathrm{~mm}$.

The advantage of the shear angle technique over the hardness-based measurement is that strain can be measured in closer proximity to the sheared edge whereas the hardness technique is limited to a distance of at least twice the size of the indenter away from the edge. A smaller hardness indenter could potentially be used to decrease the indenter spacing and hence improve resolution. However, the load must also be high enough to deform the sample over a sufficient area depending on material strength and grain size. The grain rotation method does not have such limitations and also would be valid for materials with saturating flow stress such as aluminum for which the hardness is expected to saturate with strain. The grain rotation is also directly linked to the equivalent strain in a closed form analytical relationship whereas interrupted tests are needed to establish the hardness-strain correlations. However, the grain rotation technique does require a material that is amenable to microstructural measurement of grain rotation such as the current CP and DP steels which offer a strong contrast between phases.

\subsection{Representative Strain-Distribution within the SAZ}

The point-wise strain measurements presented in Section 4.1, derived from the shear anglebased measurement technique are inherently "noisy" (Figure 20). To address the need for straindistributions that can be systematically implemented in numerical models, a representative distribution is developed in this section. Figure 29a and 30a are micrographs of the corresponding sheared samples (taken prior to hardness measurements) illustrating the features of the sheared edge (roll over, burnish, fracture and shear-burr zones). Contour maps of 
equivalent strain were calculated using the measured data across the sheared samples (shown in Figure 20 and 21) for the CP800 and DP780, respectively. Sub-regions of different sizes, 0.05 $\mathrm{mm} \times 0.05 \mathrm{~mm}, 0.1 \mathrm{~mm} \times 0.1 \mathrm{~mm}$ and $0.2 \mathrm{~mm} \times 0.2 \mathrm{~mm}$, were selected to obtain straindistributions within which the strain values were averaged. This process is similar, for example, to how DIC software employs averaging of point-wise strain measurements (Sutton et al., 2009). For each sub-region, an average Mises equivalent strain value was calculated using an arithmetic average of all discrete values from points that lie within that sub-region. Since the difference between the strain-distributions obtained along the rolling and transverse directions is not significant, the strain measurements for the two orientations were combined by averaging the Mises equivalent strains within each of the sub-regions. Figure 29 and 30 present the strain contour maps adjacent to the CP800 and DP780 sheared edges.
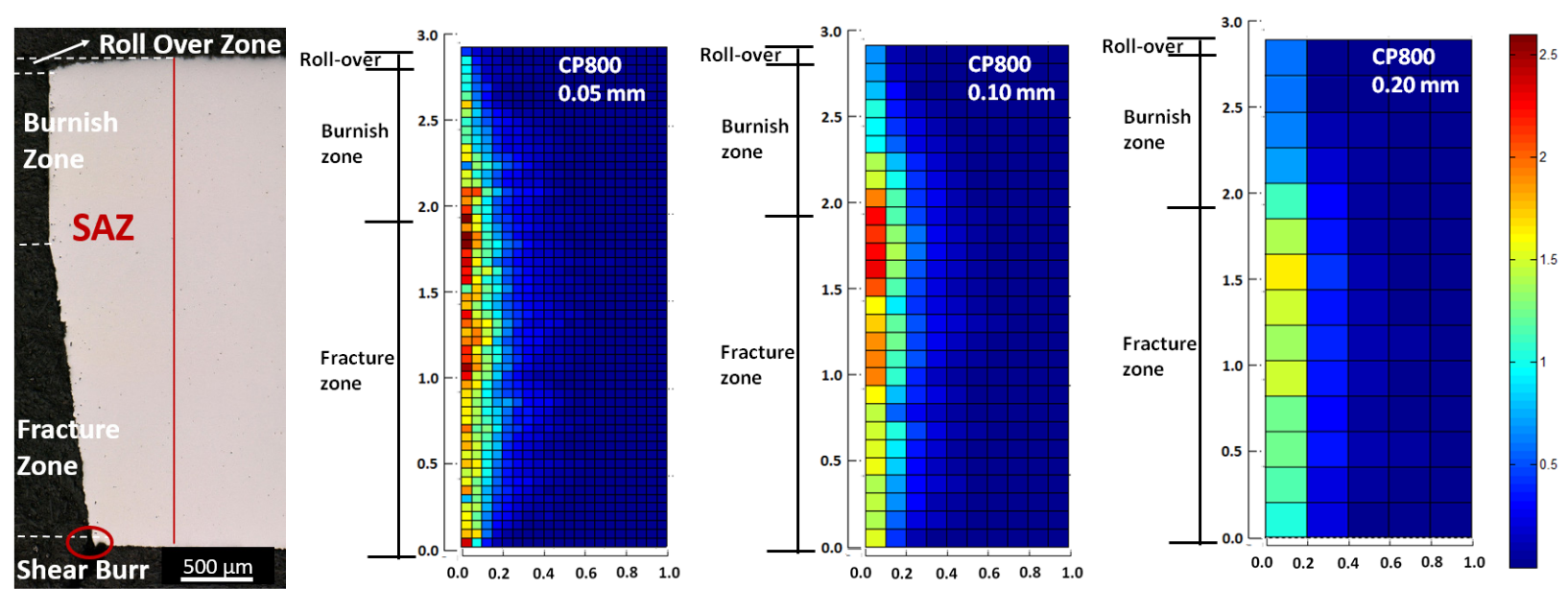

Figure 29: Representative strain-distribution as a function of distance from the sheared edge and thickness gradient for the CP800 edge sheared at 12\% clearance for different sizes of sub-region (b) $0.05 \mathrm{~mm}$, (c) $0.10 \mathrm{~mm}$ and (d) $0.20 \mathrm{~mm}$. 

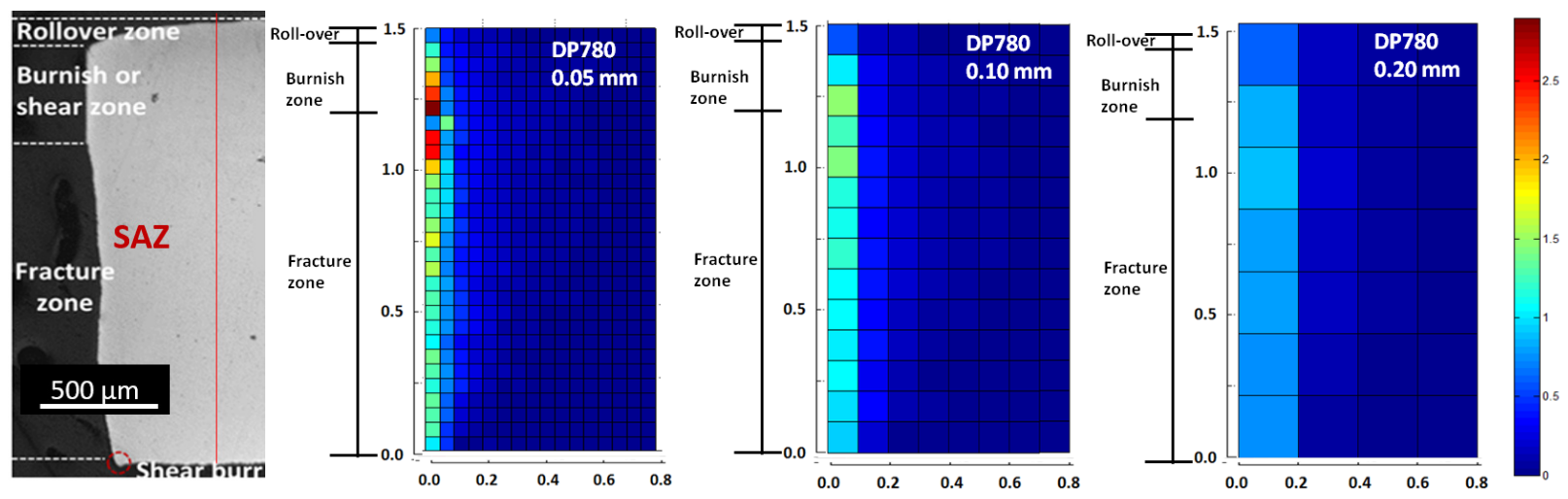

Figure 30: Representative strain-distribution as a function of distance from the sheared edge and thickness gradient for the DP780 edge sheared at $12 \%$ clearance for different sizes of sub-region (b) $0.05 \mathrm{~mm}$, (c) $0.10 \mathrm{~mm}$ and (d) $0.20 \mathrm{~mm}$.

The shear face is divided into four zones: rollover, burnish, fracture and shear-burr, as shown in Figure 29a and 30a. To investigate the strain-distribution at the sheared edge with respect to the different zones, a line slice was extracted from the zones immediately adjacent to the shear face from each of the strain contour plots and is plotted in Figure 31 for the CP800 and DP780 steels. The roll-over zone is formed due to the deformation caused by the initial penetration of the punch into the sheet. When the punch initially presses the sheet metal to shear a hole, the sheet has tendency to retain its flatness before a cut is initiated by the punch, as discussed by $\mathrm{Wu}$ et al. (2012). After the cut initiates and the punch penetrates further into the material, the straight, vertical profile of burnish zone is created at the sheared-edge. The burnish zone has a smooth surface and is a zone of relatively stable deformation and therefore the level shear strain introduced behind the burnish zone is less compared to the fracture zone which has unstable deformation and a rough surface. The crack that develops at the end of the burnish zone propagates through the thickness to create the fracture zone. A higher strain is obtained at the transition between the burnish and fracture zones where the crack deviates to form a rough fracture surface. This behavior is observed for both the ferritic-bainitic CP800 and ferriticmartensitic DP780 steels. As expected, the measured strains are higher for the strain-distribution comprising a smaller sub-region size of $0.05 \mathrm{~mm}$, an indication of the influence of length-scale on the strain measurements as further discussed in the following section. 


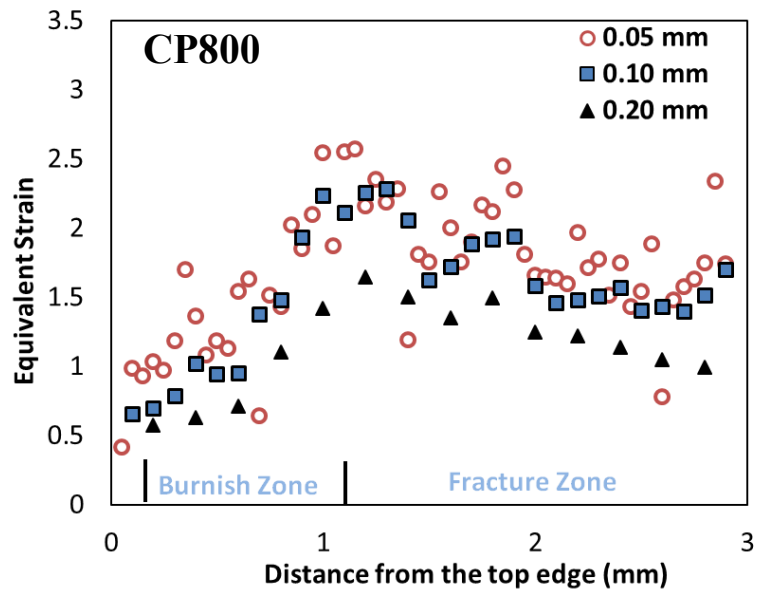

(a)

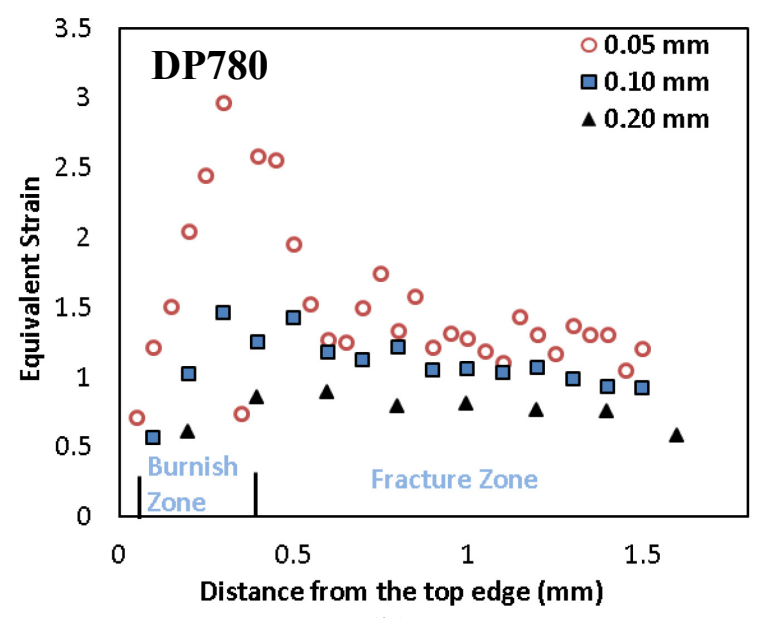

(b)

Figure 31: Line slices along the shear face extracted from the strain-distributions for the (a) CP800 and (b) DP780 steels.

\subsection{Influence of Punching Clearance on SAZ Strain-Distribution}

In industrial forming operations, the clearance of the sheared hole differs due to the shearing tool's surface quality and amount of wear. To investigate the effect of clearance on the straindistribution, shear angle measurements were conducted behind the CP800 edge sheared at 28\% clearance. Figure 32 is a micrograph of the sheared edge at $28 \%$ clearance, highlighting the rollover, burnish, fracture and shear-burr zones. The strain distribution of the SAZ was calculated from the shear angle distribution (presented in Figure 33a) using Equation 18 and is shown in Figure 33b.

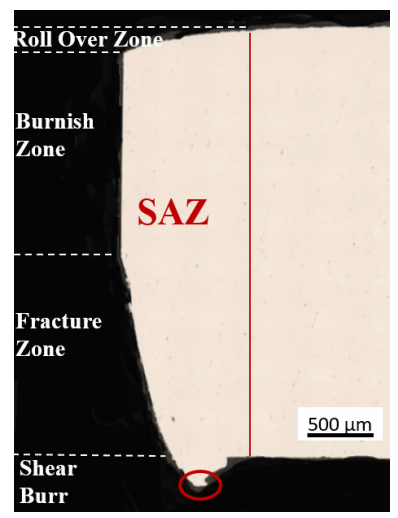

Figure 32: Sheared edge of CP800 at 28\% clearance consisting four zones: Rollover, burnish, fracture and burr 


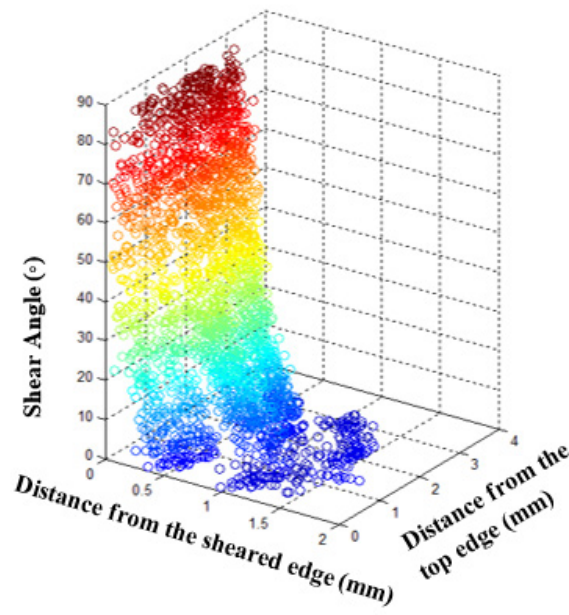

(a)

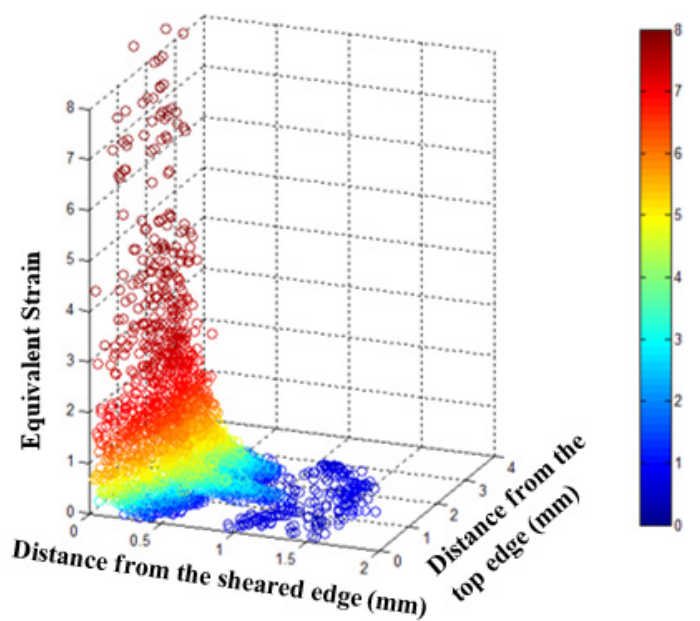

(b)

Figure 33: (a) Shear angle and (b) strain distribution as a function of distance from the sheared edge for the CP800 sheared edge at cutting clearance of $28 \%$.

The representative strain-distribution behind the edge sheared at $28 \%$ clearance is shown in Figure 34 for the sub-region of size $0.2 \mathrm{~mm}$. The size of the SAZ at $28 \%$ clearance is $1.0 \mathrm{~mm}$ is which is larger compared to the size of the SAZ at $12 \%$ clearance i.e. $0.8 \mathrm{~mm}$. With an increase in clearance, the material between the die and punch increases and consequently the size of SAZ is larger at a larger clearance. Similar trends were observed for the sub-region sizes of $0.05 \mathrm{~mm}$ and $0.1 \mathrm{~mm}$. The magnitude of the strains at the edge is higher behind the edge sheared at $28 \%$ clearance than the $12 \%$ clearance. The height of the shear-burr is also higher for the edge sheared at $28 \%$ clearance compared to the $12 \%$ clearance, as indicated in micrographs of the sheared edge (Figures 29a and 32). The shear-burr is formed due to the small amount of material that remains connected with the blank during the punching process and is separated by the tensile force. With an increase in clearance, material between the die and punch increases and so does the burr-height as observed from the micrographs. A high strain-value is reported behind the shear-burr formed at $28 \%$ clearance due to the severe deformation caused during separation from the slug. Since the size of the shear-burr is small for the edge sheared at $12 \%$ clearance, the influence of the shear-burr on the strain-distribution is negligible. The burr-height is indicative of the amount of material that undergoes deformation during the shearing process but the decrease in sheared edge formability is mainly controlled by the amount of work-hardening introduced within the SAZ (Pathak, et al., 2016). Since consideration of strain-distribution introduced during the shearing process is critical to predict sheared edge failure, the proposed techniques are 
of great interest to model sheared edge forming operations. Future work will incorporate the mapping of pre-existing strain behind the sheared edge, determined experimentally in this work, into a finite-element model to simulate edge stretching of the CP800 and DP780 steels.
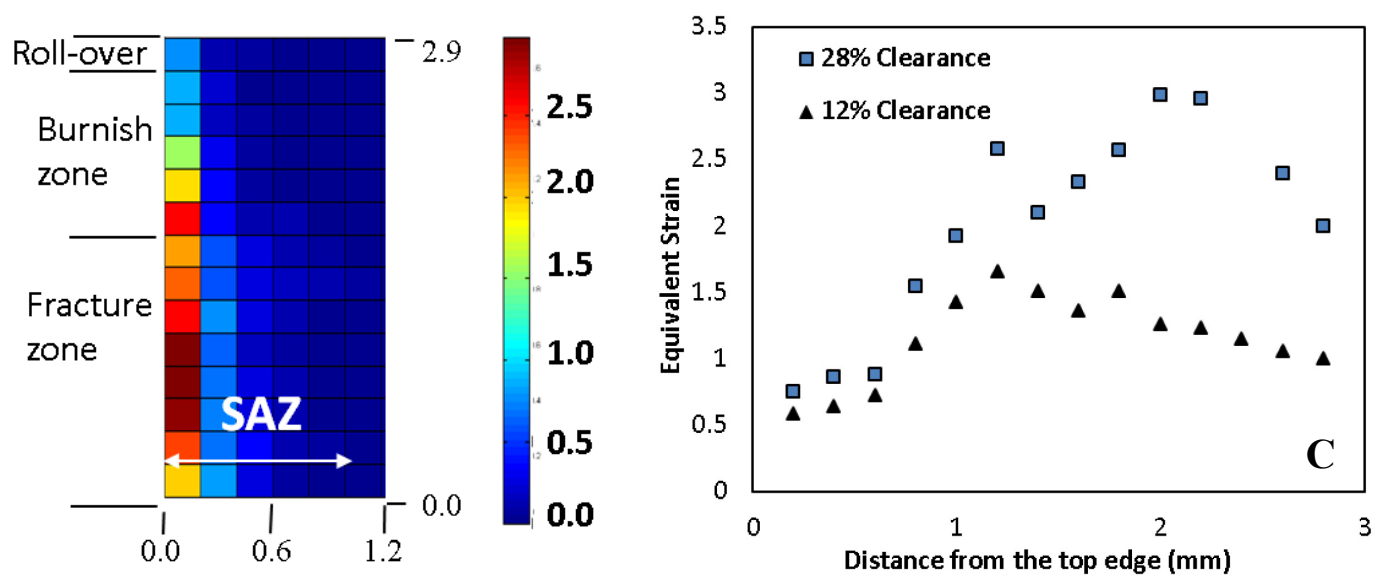

Figure 34: Representative strain-distribution as a function of distance from the sheared edge and thickness gradient for the edge sheared at $28 \%$ clearance.

\subsection{Influence of Length-Scale on Strain Measurement}

In the present work, the shear strain was obtained for each material using two different methodologies, recording the deformation of the shear specimen using DIC and measuring strain behind the sheared edge using grain rotation. The DIC failure strain of the shear specimens was extracted using a circle of diameter $0.2 \mathrm{~mm}$ and a VSGL of $0.3 \mathrm{~mm}$ as an inspector tool and the average DIC fracture strain reported for the DP780 and CP800 steels is 0.67 and 0.87 , respectively, as indicated in Figure 35. The measured strain at the sheared edge is also an indicator of fracture strain under shear loading and the average strains reported at the fractured sheared edge are shown in Figure 30 which varies along the through-thickness direction for all sizes of sub-region. To investigate the influence of length-scale on strain measurement, the failure strain is obtained from the grain rotation technique for three length-scales $(0.05,0.1$ and $0.2 \mathrm{~mm}$ ) by averaging the strain for all of the sub-regions of the line slice extracted at the shear face (shown in Figure 31). These values are plotted in Figure 35. 


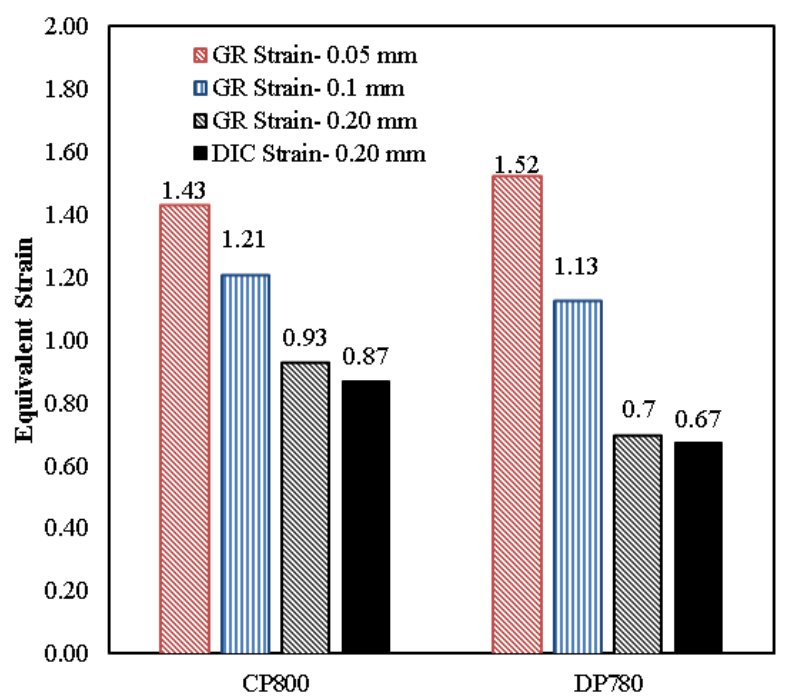

Figure 35: Influence of length-scale on the strain measurement indicated by grain rotation (GR) measurement and DIC technique

The average equivalent failure strain obtained from the shear angle measurements for different length-scales along with the DIC failure strain of the shear specimen is shown in Figure 31. The highest failure strain is obtained for $0.05 \mathrm{~mm}$ length-scale measurement and decreases with an increase in the length-scale. The strain obtained by averaging a section of $0.2 \mathrm{~mm}$ behind the sheared edge is 0.63 and 0.93 for the DP780 and CP800 steels respectively, which is very close to the failure strain obtained from the shear test because the size of inspector tool used for DIC analysis is $0.2 \mathrm{~mm}$. This result indicates that based on the length-scale of the measurement, the fracture strain under shear loading varies significantly for the materials considered. It also indicates that similar strain levels can be obtained using the two techniques if a common length scale is adopted. The grain rotation technique enables the failure strains to be determined at a higher resolution than typical DIC systems that are limited by the camera system and speckle pattern size. This result highlights the importance of choosing the appropriate gage length in shear fracture characterization and supports the recent findings of Rahmaan et al. (2017) who observed significant gage length issues arising in high rate shear tests due to the formation of adiabatic shear bands with a width on the order of 200 microns that was not resolved within the DIC system used in that study. 


\section{Conclusions}

1. Two techniques were proposed to determine local strains during shear deformation based on (a) grain rotation and (b) hardness-value. The two techniques were applied to determine the strain-distributions in CP800 and DP780 steel with good agreement obtained with both methods.

2. The equivalent strain determined using finite strain theory of simple shear was found to provide good agreement with the DIC strain measurements. The advantage of the proposed technique is that strains can be acquired at a higher resolution than the DIC system.

3. The gage length used to report the shear failure strains is critical due to the small size of the shear band at failure. A change in the gage length from 0.05 to $0.20 \mathrm{~mm}$ resulted in a reduction in the equivalent strain from 1.52 to 0.67 for the DP780 and from 1.42 to 0.87 for CP800.

4. The strain-distribution introduced during shearing varies through-thickness as well as away from the edge. At the shear face, the highest strain is observed near the transition of the burnish and fracture zones.

5. A higher strain-profile is observed for the edge sheared at $28 \%$ cutting clearance compared to the $12 \%$ clearance due to the severe local deformation introduced at a higher clearance.

Acknowledgements: Financial support for this work was provided by the Natural Sciences and Engineering Research Council of Canada (NSERC), the AUTO21 Network of Centres of Excellence and the Canada Research Chairs Secretariat. The authors would like to acknowledge the support of their industrial partner, ArcelorMittal Dofasco, with special thanks to Jeff Gao, Erika Bellhouse, Rex Holden, Pao Som and Bernie Jeffrey. 


\section{References}

Abedini, A., Butcher, C., Rahmaan, T. \& Worswick, M., 2017. Evaluation and calibration of anisotropic yield criteria in shear Loading: Constraints to eliminate numerical artefacts. International Journal of Solids and Structures, Volume In press.

Abedini, A., Butcher, C. \& Worswick, M., 2016. Fracture characterization of rolled sheet alloys in shear loading: studies of specimen geometry, anisotropy, and rate sensitivity. Journal of Experimental Mechanics, 57(1), pp. 75-88.

Abedrabbo , N. et al., 2009. Crash response of advanced high-strength steel tubes: Experiment and model. g, 36(8), pp.1044-1057.. International Journal of Impact Engineering, $36(8)$.

Anderson, D., Butcher, C., Pathak, N. \& Worswick, M., 2017. Failure parameter identification and validation for a dual-phase 780 steel sheet. International Journal of Solids and Structures, 124, pp. 89-107.

ASTM E8/E8M-11, 2011. Standard test methods for tension testing of metallic materials, West Conshohocken, PA: ASTM International.

Bae, D. \& Ghosh, A., 2003. A planar simple shear test and flow behavior in a superplastic Al-Mg alloy. Metallurgical and Materials Transactions A, 34(11), pp. 2465-2471.

Bai, Y. \& Wierzbicki, T., 2008. A new model of metal plasticity and fracture with pressure and Lode dependence. International Journal of Plasticity, 24(6), pp. 1071-1096.

Bai, Y., Wierzbicki, T. 2010. Application of extended Mohr-Coulomb criterion to ductile fracture. International Journal of Fracture, 161, pp. 1-20

Bao, Y. \& Wierzbicki, T., 2004. On fracture locus in the equivalent strain and stress triaxiality space. International Journal of Mechanical Sciences, 46(1), pp. 81-98. 
Barlat, F. et al., 2005. Linear transfomation-based anisotropic yield functions. International Journal of Plasticity, 21(5), pp. 1009-1039.

Barlat, F., Lege, D. \& Brem, J., 1991. A six-component yield function for anisotropic materials. International journal of plasticity, 7(7), pp. 693-712.

Beese, A.M., Luo, M., Li, Y., Bai, Y., Wierzbicki, T., 2010. Partially coupled anisotropic fracture model for aluminum sheets. Engineering Fracture Mechanics, 77, pp. 1128-1152.

Brosius, A., Yin, Q., Guner, A., Tekkaya, A.E., 2011. A new shear test for sheet metal characterization. Steel Research International, 82, pp. 323-328.

Butcher, C. \& Abedini, A., 2017. Shear Confusion: Identification of the Appropriate Equivalent Strain in Simple Shear using the Logarithmic Strain Measure. Volume submitted.

Cheong, K., Omer, K., Butcher, C., George, R., Dykeman, J., 2017. Evaluation of the VDA 238-100 Tight Radius Bending Test using Digital Image Correlation Strain Measurement, Proceedings of 36th International Conference of the International Deep Drawing Research Group (IDDRG 2017), Journal of Physics: Conference Series, 896, 012075, pp. 1-9

Dunand, M., Mohr, D., 2010. Hybrid experimental-numerical analysis of basic fracture experiments for sheet metals. International Journal of Solids and Structures, 47, pp. 1130-1143

Dunand, M. \& Mohr, D., 2011. Optimized butterfly specimen for the fracture testing of sheet materials under combined normal and shear loading. Engineering Fracture Mechanics, 78(17), pp. 2919-2934.

Ghahremaninezhad, A., Ravi-Chandar, K., 2013. Ductile failure behavior of polycrystalline $\mathrm{Al}$

Herrmann, K., 2011. Hardness testing: principles and applications. s.1.:ASM International.

Hollomon, J., 1945. Tensile deformation. AIME TRANS, 12(4), pp. 1-22.

ISO/TS , 2009. Metallic materials - method of hole expanding test, s.l.: s.n. 
Japan Iron \& Steel Federation Standard,, 1996. Method of hole expanding test, s.1.: s.n.

Johnson, G.R., Cook, W.H., (1985). Fracture characteristics of three metals subjected to various strains, strain rates, temperatures and pressures. Engineering Fracture Mechanics, 21, pp. $21-48$

Levy, B. \& Van Tyne, C., 2012. Review of the Shearing Process for Sheet Steels and Its Effect on Sheared-Edge Stretching. Journal of materials engineering and performance, 21(7), pp. 1205-1213.

Luo, M., Wierzbicki, T., 2010. Numerical failure analysis of a stretch-bending test on dual phase steel sheet using a phenomenological fracture model. International Journal of Solids and Structures, 47, pp. 3084-3102

Mohr, D., Henn, S., 2007. Calibration of stress-triaxiality dependent crack formation criteria: a new hybrid experimental-numerical method. Experimental Mechanics, 47, pp. 805820 .

Onaka, S., 2012. Comment on "A comparison of the von Mises and Hencky equivalent strains in simple shear experiments. Philosophical Magazine,, Volume 92, pp. 2264-2271.

Papasidero, J., Doquet, V., Mohr, D., 2015. Ductile fracture of aluminum 2024-T351 under proportional and non-proportional multi-axial loading: Bao-Wierzbicki results revisited. International Journal of Solids and Structures, 69-70, pp. 459-474.

Pathak, N., Butcher, C. \& Worswick, M., 2016. Assessment of the Critical Parameters Influencing the Edge Stretchability of Advanced High Strength Steel. Journal of Materials Engineering and Performance, 25(11), pp. 4919-4932.

Pathak, N. et al., 2017. Damage Evolution in Complex-Phase and Dual-Phase Steels during Edge Stretching. Materials, 10(4), pp. 346.

Peirs, J., Verleysen, P. \& Degrieck, J., 2012. Novel technique for static and dynamic shear testing of Ti6Al4V sheet. Volume 52, pp. 729-741. 
Pohlandt, K., Tekkaya, A.E. (1985). Torsion testing - plastic deformation to high strains and strain rates. Material Science Technology, 1, pp. 972-977.

Rahmaan, T. et al., 2017. Investigation into the ShearStress, Localization and Fracture Behavior of DP600 and AA5182-O Sheet Metal Alloys under Elevated Strain Rates.. International Journal of Impact Engineeing.

Rice, J.R., Tracey, D.M., (1969). On the ductile enlargement of voids in triaxial stress fields. Journal of the Mechanics and Physics of Solids, 17, pp. 201-217.

Roth, C.C., Mohr, D., 2016. Ductile fracture experiments with locally proportional loading histories. International Journal of Plasticity, 79, pp. 328-354.

Scales M., Tardif N., Kyriakides S., (2016). Ductile failure of aluminum alloy tubes under combined torsion and tension. International Journal of Solids and Structures, 97-98, pp. 116-128.

Shrivastava, S., Ghosh, C. \& Jonas, J., 2012. A comparison of the von Mises and Hencky equivalent strains for use in simple shear experiments.. Philosophical Magazine, Volume 92, pp. 779-786.

Sutton, M. A., Orteu, J. J. \& Schreier, H., 2009. Image Correlation for Shape, Motion and Deformation Measurements. s.1.:Springer.

Swift , H., 1952. Plastic instability under plane stress. Journal of Mechanics and Physics of Solids, 1(1).

Wang, K., Greve , L. \& Wierzbicki, T., 2015. FE simulation of edge fracture considering pre-damage from blanking process. International Journal of Solids and Structures, Volume 71, pp. 206-218.

Wu, X., Bahmanpour, H. \& Schmid, K., 2012. Characterization of mechanically sheared edges of dual phase steels. Journal of Materials Processing Technology, 212(6), pp. 1209-1224.

Yin, Q., Zillmann, B., Suttner, S., Gerstein, G., Biasutti, M., Tekkaya, A., Wagner, M., Merklein, M., Schaper, M., Halle, T., Brosius, A. 2014. An experimental and numerical 
investigation of different shear test configurations for sheet metal characterization. International Journal of Solids and Structures, 51, pp. 1066-1074.

Zener, C. \& Hollomon, J., 1944. Effect of strain rate upon plastic flow of steel. Journal of Applied Physics, Volume 15, pp. 22-32.

Zhou, X. \& Tamma, X., 2003. On the applicability and stress update formulations for corotational stress rate hypoelasticity constitutive models. Finite Elements in Analysis and Design, Volume 39, pp. 783-816. 